\title{
EL MATRIMONIO ESPIRITUAL ENTRE OBISPO E IGLESIA. ORIGEN Y DESARROLLO DURANTE LA FORMACIÓN DEL «CORPUS IURIS CANONICI»
}

Fecha de recepción: 24 de abril de 2019

Fecha de aceptación y versión final: 25 de septiembre de 2019

RESUMEN: Analizamos el nacimiento de la metáfora del matrimonio espiritual entre obispo e Iglesia en el siglo IV, y su posterior desarrollo durante la formación del Corpus Iuris Canonici (XI-XV), principalmente en el Occidente de la cristiandad. Para ello procedemos a la lectura de diversas fuentes interdisciplinares, que revelan la irregular evolución e implementación de la metáfora en diversos ámbitos de la emergente ciencia canónica y de la teología. Concluimos estableciendo el iter seguido por la metáfora en la teología del ministerio episcopal, y acorde a la evolución de la Eclesiología: de obispo prevalentemente esposo de su iglesia, a obispo representante de Cristo —único Esposo-, unido por un doble vínculo con la Iglesia universal y con la iglesia particular.

PALABRAS CLAVE: Iglesia; obispo; matrimonio espiritual; derecho canónico.

\footnotetext{
* Juez del Tribunal Eclesiástico de la Archidiócesis de Barcelona. Defensora del vínculo de la Diócesis de Solsona y Promotora de Justicia de la Diócesis de Vic: aramago7@gmail.com
} 


\section{The Spiritual Marriage between Bishop and Church. Origin and Development during the Formation of the "Corpus Iuris Canonici»}

ABSTRACT: We analyze the birth of the metaphor of spiritual marriage between bishop and Church in the fourth century, and its subsequent development during the formation of the Corpus Iuris Canonici (XI-XV), mainly in the West of Christianity. For this we proceed to the reading of diverse interdisciplinary sources, which reveal the irregular evolution and implementation of the metaphor in various areas of the emerging canonical science and theology. We conclude by establishing the iter followed by the metaphor in the theology of the episcopal ministry, and according to the evolution of Ecclesiology: from bishop prevalently husband of his church, to the representative bishop of Christ - the only Spouse-, united by a double bond with the Universal church and with the particular church.

KEY WORDS: Church; bishop; spiritual marriage; canon law.

\section{INTRODUCCIÓN}

En el contexto de las exhortaciones que el papa Francisco ha dirigido a los obispos durante su pontificado, se hallan estas palabras:

«Sois esposos de vuestra comunidad, ligados profundamente a ella. Os pido, por favor, que permanezcáis en medio de vuestro pueblo [...] Evitad el escándalo de ser "obispos de aeropuerto" [...]. Por favor, nosotros pastores no somos hombres con la "psicología de príncipes" - por favor-, hombres ambiciosos, que son esposos de esta iglesia en espera de otra más bella o más rica. ¡Esto es un escándalo! Si viene un penitente y te dice: "Yo estoy casado, vivo con mi mujer, pero miro continuamente a aquella mujer que es más bella que la mía: ¿es pecado, padre?”. El Evangelio dice: es pecado de adulterio. ¿Existe un "adulterio espiritual"? No sé, pensadlo vosotros. No estar a la espera de otra más bella, más importante, más rica. ¡Estad bien atentos en no caer en el espíritu del carrerismo!»!

El texto reclama un clásico argumento interdisciplinar, versátil y polémico que surge de las primitivas fuentes canónicas: el matrimonio espiritual entre obispo e Iglesia. Singular metáfora que establece una transitividad comparativa de sentido entre el sacramento del

1 "Discurso del Santo Padre Francisco a los participantes en el Congreso para los obispos de nuevo nombramiento organizado por la congregación para las Iglesias orientales", Sala Clementina, 19 de septiembre de 2013, http://www.vatican.va. 
matrimonio contraído por los cónyuges a imagen de la unión de Cristo y la Iglesia (Ef 5,25-33), y el vínculo simbólicamente nupcial contraído por obispo e Iglesia. Metáfora que ha evolucionado a lo largo de los siglos, permaneciendo siempre viva suo modo.

Adentrarnos en su origen supone asumir la cercanía que desde los albores de la Iglesia se observa entre la simbología mística y las formulaciones rigurosamente teológicas y jurídicas. Sabido es que el derecho canónico, connatural a la Iglesia como sacramento de salvación ${ }^{2}$, pertenece al plano sobrenatural de la fe y solo puede ser comprendido en relación a la Palabra de Dios y a los sacramentos, siendo necesaria para la exposición de la ciencia canónica la presencia del misterio de la Iglesia ${ }^{3}$.

El presente estudio configura el origen de la metáfora entorno a tres ejes: el arcano concepto de «adulterio espiritual», la arraigada expresión ecclesia viduata y la definición paulina del obispo como unius uxoris virum (1Tim 3,2-12; Tit 1,6). Seguidamente afloran, en el texto, de manera básicamente cronológica, el íter que sigue la metáfora en el Medioevo y su irregular evolución, marcada por la irrupción de la colección canónica de las Falsas Decretales en el siglo IX y su práctica utilización en la polémica Reforma gregoriana. A ello se añade el protagonismo que le concede Inocencio III a principios del XIII, seguido por la tradición decretalista, para acabar con unos apuntes sobre el tema desde la óptica de la teología y la espiritualidad de la época.

\section{EL ORIGEN}

Cabe reconocer que, seguramente, la realidad asociativa más adecuada para comprender la vida e identidad estructural de la Iglesia, la más cercana, sea la familia en su sentido más amplio ${ }^{4}$. En la Antigüedad cristiana, en continuidad con el judaísmo, los conceptos familiares ayudan en la construcción de la comunidad eclesial, articulando la

2 Cf. G. Ghirlanda, "El valor del derecho canónico para la misión de la Iglesia", Ius Communionis 6 (2018): 69-103.

3 Concilio Vaticano II, Decreto sobre la formación sacerdotal, Optatam totius, n. ${ }^{\circ}$ 16, 28 de octubre de 1965, AAS 58 (1966), 713-727.

${ }^{4}$ Cf. Ricardo Blázquez, Josep M. Soler y Olegario González de Cardedal, El obispo en la Iglesia: una meditación (Madrid: San Pablo, 2002), 112-115. 
variedad de relaciones surgidas de la nueva vida nacida del sacramento del bautismo ${ }^{5}$.

En el siglo IV la idea de «matrimonio espiritual», es decir, de un vínculo místico de características comparables al matrimonio carnal ${ }^{6}$, es comúnmente usada para formular la relación entre Cristo y la Iglesia, entre el alma y Dios, y también para fijar el estatuto de las mujeres con voto de virginidad ${ }^{7}$. Su incipiente uso para definir la unión de obispo e Iglesia se vierte ahora en el diseño de la institución del episcopado.

Sabido es que en los más importantes testimonios canónicos y litúrgicos de los tres primeros siglos, la vida de las comunidades locales gira entorno a la figura del obispo, representante visible de Cristo por la sucesión apostólica ${ }^{8}$. El obispo es definido icónicamente como pastor, padre, mártir, doctor, misionero, defensor civitatis, etc., pero sobre todo es considerado como el hombre de su iglesia, unida a él para toda la vida9. Por ello el oficio episcopal se presenta indisociable de la iglesia que preside, pero siempre ejercitado en los vínculos de comunión, en la fe y en la disciplina con los obispos vecinos ${ }^{10}$.

Durante la pax costantiniana impera la necesidad de normas conciliares homogeneizantes que tutelen la integridad de las circunscripciones eclesiásticas y la movilidad clerical ${ }^{11}$. Para ello se presenta útil un

${ }^{5}$ Cf. Charles J. Brown, "The development of the concept of the spousal relationship between bishop and local church in the west to the ninth century" (Tesis de doctorado, Pontificio Ateneo Anselmiano, 2009), 1.

" Cf. Reginald Grégoire, "Il matrimonio mistico", en Il matrimonio nella società altomedievale, II, Settimane di studio del centro italiano di studi sull'alto Medioevo, 24 (Spoleto: Presso la Sede del Centro, 1977), 701-817.

7 Cf. René Metz, La consécration des vierges: hier, aujourd'hui, demain (Paris: Cerf, 2001), 61-63; María M. Benites, La consagración en el ordo virginum (Buenos Aires: Cerf, 2005), 75-77.

8 Para Ignacio de Antioquía (v. † 114) e Ireneo de Lión († 202) la comunidad de fe es consciente de estar representada y sostenida por su obispo en una especie de recíproca inclusión, definida por Cipriano de Cartago $(\dagger 258)$ con la fórmula: scire debes episcopum in ecclesia esse et Ecclesiam in episcopo. Cf. PL 4,406, 317-320.

$9 \mathrm{Cf}$. Gregory Dix, Le ministère dans l'Église ancienne, des années 90 à 410 (Neuchâtel: Delachaux et Niestle, 1955), 126.

10 Cf. Condorelli, "Ejercicio del ministerio y vínculo jerárquico en la historia del derecho de la Iglesia", Ius Canonicum 45 (2005): 493-496.

11 Cf. Orazio Condorelli, Ordinare-Iudicare. Ricerca sulle potestà dei vescovi nella Chiesa antica e altomedievale, secoli II-IX (Roma: Il Cigno, 1997), 107-112. 
nexo que vincule, en términos de taxativa exclusividad, a cada obispo con su iglesia según las propiedades esenciales de la unidad y de la indisolubilidad del matrimonio cristiano, dotrina pacíficamente aceptada, que empieza a desarrollarse con fuerza en la época ${ }^{12}$.

De este modo, bajo el perfil de la unidad, se afianza paulatinamente la regla de un solo obispo por cada ciudad, es decir, el principio del episcopado monárquico ${ }^{13}$. Bajo el perfil de la indisolubilidad se ponen de relieve los estrechos límites impuestos a la movilidad clerical, que en el primer milenio generan la prohibición - al menos en modo relativo- de los traslados episcopales ${ }^{14}$, frecuentemente asimilados a adulterios espirituales ${ }^{15}$. Así pues, deviene polémica la cuestión del paso de los obispos de una sede a otra, en relación a la voluntad de acabar de facto con las ordenaciones absolutas ${ }^{16}$.

Otros dos aspectos salen a la luz en relación a lo expuesto: el principio electivo, es decir, el vínculo tendencialmente indisoluble que une a una iglesia y a su obispo, derivado del hecho de que el obispo es escogido por el cuerpo de la misma iglesia con su consenso ${ }^{17}$; y la evolución doctrinal del instituto del celibato clerical. En efecto, la compleja historia de la renuncia de los obispos a los lazos familiares naturales

12 Cf. Jean Gaudemet, Il matrimonio in Occidente (Torino: SEI, 1987), 39-41.

13 A principios del siglo III, a pesar del proceso poco uniforme de implantación del episcopado monárquico, existen escasas huellas de un episcopado colectivo. Cf. Cornelia Vogel, "Unidad de la Iglesia y pluralidad de las formas históricas de organización eclesiástica desde el siglo III al V”, en El Episcopado y la Iglesia Universal, ed. Yves Congar y Bernard Dupuy (Barcelona: Estela, 1966), 540.

${ }^{14}$ En el siglo V, en la Galia, se admite ya la posibilidad del traslado de sede en caso de necesidad para el bien de la Iglesia. La legislación se orienta progresivamente hacia la regulación y no hacia la prohibición total. Cf. Charles Munier, Les Statuta Ecclesiae Antiqua (Paris: Édition-Études, 1960), 131-133.

15 Cf. Leo Ober, "Die Translation der Bischöfe im Altertum”, Archiv für katholisches Kirchenrecht 88 (1908): 222-224.

16 Según el canon 6 del Concilio de Calcedonia (451) las ordenaciones no destinadas a un ministerio determinado, o sea, sine titulo, eran nulas. Cf. Condorelli, "Ejercicio del ministerio", 496-501; Cf. Jean Gaudemet, L'Église dans l'empire romain, IV-V siècles (Paris: Sirey, 1958), 111-113.356-363. V. Fuchs sostiene que la idea del «obispo esposo» fue causa de la imposibilidad teórica general de las ordenaciones absolutas en el primer milenio. Cf. Vincent Fuchs, Der Ordinationstitel von seiner Entstehung bis auf Innozenz III (Bonn: Schroeder, 1930), 1, 69, 132.

17 Cf. Orazio Condorelli, Principio elettivo, consenso, rappresentanza (Roma: Il Cigno, 2003), 16-17. 
operada por la disciplina — primero de la continencia ${ }^{18}$ y después del celibato- fue justificada a menudo por la asunción de nuevos vínculos familiares de tipo espiritual. Si bien el canon 33 del Concilio de Elvira (v. 306) ya prohibía a los eclesiásticos las relaciones sexuales, los documentos que precisan la disciplina en materia de continencia de los clérigos son de los años 380 y 390, décadas muy cercanas a la aparición de la metáfora sobre el matrimonio espiritual entre obispo e Iglesia ${ }^{19}$.

En el ámbito dogmático y exegético, la metáfora se enraiza en el Nuevo Testamento, en el ya citado misterio nupcial referido a Cristo y a la Iglesia, y en otros pasajes de san Pablo (cf. 1Cor 7,27; 2Cor 11,2), especialmente en el que afirma la necesidad de que los obispos sean unius uxoris virum (1Tim 3,2-12; Tit 1,6), es decir, hombres de una sola espo$\mathrm{sa}^{20}$. Se trata de textos que la Patrística interpreta, a menudo, reflexionando alegóricamente y ampliamente sobre la condición del ministro ordenado como representante de Cristo esposo (cf. Mt 22,1-14; Mc 2,20; Jn 3,29; Ap 5,6.21).

\section{ADULTERIO ESPIRITUAL}

La teoría de que un obispo que se traslada a otra diócesis comete delito de adulterio espiritual por abandonar a su esposa legítima, la iglesia para la cual ha sido nombrado, para esposar a otra, se afianza en el siglo IV.

Si bien ya Cipriano de Cartago había acusado al presbítero Novaciano $(† 258)$ de adúltero por su deseo de ocupar la sede romana, de la cual el papa Cornelio $(\dagger 253)$ era su legítimo titular ${ }^{21}$, el primer texto en

18 El pontífice León Magno († 461) recomienda que las mujeres de los clérigos no sean abandonadas, sino tomadas como compañeras en un spirituale coniugium con la finalidad de salvaguardar el amor mutuo, es decir, la caritas connubiorum. Cf. PL 54,1201-1204.

19 Cf. Christian Cochini, Origines apostoliques du célibat sacerdotal (Paris: Lethielleux, 1981), 38; Laurent Touze, L'Avenir du celibat sacerdotal et sa logique sacramentelle (Paris: Parole et silence, 2009), 113-187.

${ }^{20}$ A partir de la legislación del siglo IV son muy abundantes las normas que exigen que los eclesiásticos sean ordenados unius uxoris virum, es decir, que no se hayan casado diversas veces, bigamii sucesivos, $\mathrm{u}$ hombres que no se hayan casado con una mujer que no era virgen. Cf. Gaudemet, L'Église dans l'empire, 140-141.

21 Cf. PL 3,703. 
el cual se explicita el argumento es de un fiel defensor de la doctrina del Concilio de Nicea (325) ${ }^{22}$ : el patriarca Atanasio $(† 373)^{23}$.

En el Sínodo de Alejandría (v. 340) Atanasio reprende al obispo arriano Eusebio de Nicomedia $(† 341)$ por querer invalidar su ordenación debido a su traslado de Nicomedia a Constantinopla, y por rechazar el destino divino para el cual ha sido predestinado. Así pues, Eusebio, es recriminado por no haber respetado el precepto paolino: «¿estás unido a una mujer? No busques la separación» (1Cor 7,27). Si esto se dice de una mujer — explica el Patriarca-, es aún más válido para la iglesia y para el obispo vinculado a ella, que no debe convertirse en adúltero según la Sagrada Escritura:

«Ubi duo aut tres in nomine Domini congregati fuerint, illic esse Dominum in medio eorum, ne secum recogitans dictum illud Apostoli; non alienis laboribus gloriabor: neque prae oculis habens illius praeceptum: Alligatus est uxori, noli quaerere solutionem. Quod si hoc de uxore dictum est, quanto magis de ecclesia, atque adeo de episcopatu, quicum quis alligatus est, alium quaerere non debet, ne adulter ex sacris litteris deprehendatur ${ }^{24}$.

Otros testimonios de la Patrística dan fe del argumento. Gregorio de Niza (†395) —obispo casado—, considera adúltero al obispo Pablo de Antioquía por haber entrado en el lecho matrimonial de la esposa de Cristo, es decir, la iglesia de Antioquía, cuando Melecio ( $\dagger$ v. 381) era todavía su obispo $^{25}$. También Evragio Escolástico († v. 593) en su obra Historia Eclesiástica señala que el paso a otra sede se convierte en un adulterio ${ }^{26}$.

En el ámbito de la legislación, el citado canon 15 del Concilio de Nicea, a pesar de declarar nulo el traslado de los clérigos, no fija punición

${ }^{22}$ El canon 15 establece el cambio de sede de los obispos, sacerdotes y diáconos como motivo de confusión y polémica, y por ello nulo; y el canon 8 expone el principio que excluye la multiplicidad de obispos en una misma diócesis. Cf. Norman Tanner y Giuseppe Alberigo, Decrees of the Ecumenical Councils, I (London: Sheed \& Ward, 1990), 9, 13.

${ }^{23}$ Cf. Josef Trummer, "Mystiches im alten Kirchenrecht. Die geistige Ehe zwischen Bischof und Diözese”, Oestereichisches Archiv für Kinchenrecht 2 (1951): 63; J. Gaudemet, "Le symbolisme du mariage entre l'évêque et son Église et ses consequences juridiques”, Kanon 7 (1985): 110.

24 MANSI 2, 1285-1287.

25 Cf. PG 36,273.

26 Cf. PG 86,2526. 
alguna. Pero pocos años después, el primer canon del Concilio de Sárdica (343/347) prohibe la práctica de los obispos -llevada a cabo especialmente por los arrianos- de pasar de una sede a otra para extender más fácilmente la herejía, imponiendo la pena de excomunión, de la cual nadie podía ser absuelto ni siquiera en caso de muerte ${ }^{27}$. De este modo, parece ser trasladada la pena aplicada al adulterio carnal, al adulterio espiritual ${ }^{28}$.

El argumento se afianza en siglos posteriores. A modo de ejemplo, el pontífice Nicolás I († 867) aplica el término «adúltero»al obispo Photio por su acceso al trono patriarcal de Constantinopla ${ }^{29}$.

Sabida es, al final del siglo IX, la controversia sobre la elección del papa Formoso ( $† 896)$, considerada no válida por sus adversarios. Entre otros crímenes, Formoso es acusado del delito de bigamia, ya que había sido elegido obispo de Roma tras haber sido obispo de la diócesis de Porto. Así pues, había abandonado a su iglesia para esposar a otra. El delito es considerado de tanta gravedad que, su sucesor, Esteban VI († 897) exhuma su cadáver y lo somete a juicio arrojándolo después al río Tíber, en el así llamado «Concilio cadavérico».

También en el Oriente jacobita la metáfora se aplica para rechazar los traslados episcopales. En el Livre du Guide, di 'Ibn Djarir 'At-Takriti († después del 1094) el vínculo de un obispo con su diócesis se convierte en un auténtico matrimonio que solo puede ser disuelto por la muerte, y el cambio de diócesis equivale al divorcio e incluso al adulterio ${ }^{30}$. Tres siglos más tarde el metropolitano Ebedjésus Bar-Berika († 1318), escribe:

«Placuit [...] ut non possit episcopus relinquere sedem suam, in qua episcopus constitutus fuit, et migrare ad aliam, quoniam in hoc etiam saeculo omnis qui relinquit uxorem suam sine causa adulterii, et ducit aliam, adulterium committit» ${ }^{31}$.

${ }_{27}$ Cf. Karl J. Hefele y Henri Leclerq, Histoire des Conciles, I, 2 partie (Paris: Letouzey et Ané, 1907), 761.

${ }_{28}$ Cf. Ober, "Die Translation der Bischöfe", 222-224. A pesar de ello, la sanción de la excomunión es tan frecuente en la legislación eclesiástica de la época, que no siempre se debe pasar automáticamente de la identidad de sanciones a la asimilación de los dos hechos delictivos. Cf. Gaudemet, L'Église dans l'Empire, 359.

${ }^{29}$ Cf. MGH Ep. VI, 519.

30 S. Jargy, "'Ibn Djarir 'at-Takriti” en Dictionnaire du Droit Canonique, 5 (Paris: Letouzey, 1953), 1249.

31 Ebediesus bar Berika, "Ebediesu Sobae id est Nisibis metropolitae collection canonum synodicorum", en Scriptorum veterum nova collectio e vaticani codicibus, X, ed. Angelo Mai (Roma: Collegium Urbanum, 1838), 140. 


\section{4. «ECCLESIA VIDUATA»}

Son los Padres de la Iglesia quienes empiezan a aplicar el adjetivo «viuda» a la sede vacante, carente de obispo. La expresión ecclesia viduata alcanza una perdurable popularidad.

Los primeros testimonios nacen en el ámbito de las oraciones fúnebres episcopales. En una de ellas Gregorio de Niza utiliza el concepto de viudez para la iglesia que ha perdido a su marido ${ }^{32}$.

También se atribuye al papa Dámaso († 384) la clásica prescripción canónica de que una iglesia no permanezca viduata más de tres meses ${ }^{33}$, norma que recoge posteriormente el canon 25 del Concilio de Calcedonia (451) usando el mismo lenguaje ${ }^{34}$, así como algunos pontífices posteriores $^{35}$.

Las fuentes magisteriales del siglo IX continuan usando frecuentemente la expresión ecclesia viduata. Esto puede constatarse, por una parte, en los escritos de los pontífices, de León IV $(† 855)^{36}$ a Esteban V $(\dagger 891)^{37}$, entre los cuales destacan los escritos del ya citado Nicolás I ${ }^{38}$; y por otra parte en los concilios carolingios, orientados a la restauración disciplinar de la jerarquía ${ }^{39}$. También aparece la expresión en la colección de las Falsas Decretales $(847 / 852)^{40}$ y en autores coetaneos como Hincmarus de Reims $(\dagger 882)^{41}$.

32 Cf. PG 46,852.

33 Cf. PL 13,1216.

34 Cf. Tanner, 8.

35 Pelagio I ( $†$ 561) explica en una decretal que los metropolitanos deben ayudar a las viduatae ecclesiae ordenando obispos. Cf. PL 187,473; Gregorio I ( $† 604)$ afirma en la carta dirigida a un prelado que la «ecclesia Dei diu viduata proprio episcopo non debet remanere». MGH Aa, VI,488; Adriano I ( $†$ 795) se expresa usando conceptos similares. Cf. PL 98,416; PL 98,431.

36 Cf. PL 129,1001.

37 Cf. PL 129,799. Véase también: Adriano II († 872). Cf. PL 122,1270; Juan VIII $(\dagger 882)$. Cf. PL 126,947; la carta de Louis le Germanique al papa Adriano II en el año 870. Cf. MGH Ep. VI,248; y a los obispos de la Provincia de Reims en el asunto de Arnulphe de Reims hacia el año 991. Cf. PL 139,311.

38 Cf. PL 119,785. 841-842.

39 Concilio Parisiense (829). Cf. MGH Conc. II, 631.675; Concilio de Thionville (844). Cf. MGH Cap. II,114; Concilio de Yütz (844). Cf. MGH Conc. III,31; Concilio de Meaux (845). Cf. MGH Conc. III,95. Cf. Brown, 31-36.

40 Cf. PL 130,133.

${ }^{41}$ Cf. PL 126,228. 
Fuentes posteriores recogen la expresión. Por ejemplo, una crónica sobre la diócesis de Cambrai (1041/1043), donde se refleja en género poético y con lenguaje nupcial la tristeza de la iglesia viuda en la descripción de la elección del arzobispo Manasse ${ }^{42}$. En la misma línea, a finales del siglo X, en Reims, Abbo Floriacensis, aplica al obispado el sustantivo viduatio ${ }^{43}$.

En el ámbito de la Reforma gregoriana, el pontífice Gregorio VII $(\dagger 1085)$, usa en sus escritos el concepto de viudez de las iglesias vacantes ${ }^{44}$. En el Decreto de Graciano (v. 1140) ${ }^{45}$ y en colecciones canónicas posteriores como la Summa Coloniensis (v. 1169) ${ }^{46}$ se plasma la expresión ecclesia viduata con sus variantes lexicales.

Del siglo XII al XIV este lenguaje podemos considerarlo ya tradicional. Por eso en los cánones 23 y 24 del IV Concilio de Letrán (1215), en el contexto regulador de gestión de los bienes de la iglesia particular, se define nupcialmente la vacante de una sede episcopal ${ }^{47}$.

Diversos autores apuestan por la expresión. Eadmer, en Canterbury, utiliza el adjetivo viduata para calificar a la diócesis ${ }^{48}$. Bruno de Segni $(†$ 1123), inspirándose en la tradición exegética de la Ley del levirato (cf. Dt 25,5-10; Rut 4,6-7), presenta a una iglesia viuda en búsqueda de otro esposo para asegurar una descendencia a su difunto cónyuge ${ }^{49}$; y el patriarca de Constantinopla, Germano II, en 1226, para resolver un conclicto entre un obispo y sus fieles, diseña un paralelo entre la ciudad viuda y el divorcio, subrayando claramente el sentido conyugal de la expresión ${ }^{50}$.

En definitiva, la perdurabilidad de la expresión ecclesia viduata demuestra que la huella del coniugium spirituale entre obispo e iglesia se afianza en el Medioevo. Lo demuestra también el léxico del latín medieval que define la dotación de una iglesia como sponsalia o sponsalicium;

42 Cf. MGH Ldl. III,622-641.

43 Cf. PL 135,284.

${ }_{44}$ Cf. PL 148,391.504.

${ }^{45}$ C. 7 , q. 1, c. 39 ; D 75 , c. 2; D 100, c. 1 .

46 Cf. «Monumenta Iuris Canonici», Series A: Corpus Glossatorum, I, ed. Gerard Fransen y Stephan Kuttner (New York: Fordham University Press, 1969), 130.

47 Cf. Tanner, 46.

48 Cf. PL 159,776.

49 Cf. PL 164, 532-533.

50 Cf. "Codificazione canonica orientale, fonti", en Serie II, Fascicolo III, Patriarchatus Constantinopolitani Acta Selecta, I, ed. Jean Oudot (Città del Vaticano: Typis Polyglotis Vaticanis, 1941), 65. 
y que considera nupcial la entrada de un nuevo obispo en una iglesia en ocasión de su consagración ${ }^{51}$.

\section{5. «UNIUS UXORIS VIRUM»}

Al difundido uso del concepto de adulterio espiritual y de la expresión ecclesia viduata, conviene añadir la temprana interpretación alegórica de la cita neotestamentaria unius uxoris virum (cf. 1Tim 3,2-12; Tit 1,6). En ella Pablo exhorta a los obispos a ser hombres de una sola esposa, constituyéndose el texto como fundamento de la propiedad esencial de la unidad del matrimonio entre el obispo y su iglesia.

Se trata de una exégesis formulada ya por los Padres de la Iglesia, a pesar de no ser compartida por todos. En efecto, Jerónimo ( $† 420)$, el gran Padre de la Iglesia de Occidente, en su epístola Ad Oceanum no acepta la interpretación alegórica del citado texto paolino. El autor defiende al obispo Craterio de la acusación de bigamia porque, a su parecer, el argumento de la alianza conyugal entre el obispo y su iglesia es forzado, defendido por algunos para apoyar la prohibición del Concilio de Nicea de los traslados episcopales ${ }^{52}$.

También en Oriente, en el siglo XI, el arzobispo Théophylacte rechaza la interpretación por la cual l'unius uxoris virum deba aplicarse al obispo y a su iglesia y, en consecuencia, no considera adulterio espiritual el paso de una sede episcopal a otra ${ }^{53}$.

Por otra parte, tal y como desgranamos más adelante, la exégesis del texto se proyecta también en la polémica entorno a la disciplina del celibato. Da fe de ello, a modo de ejemplo, un sermón sobre el episcopado atribuido al papa Silvestre $(\dagger 1003)$ el cual considera que el obispo solo puede ser llamado hombre de una sola esposa, es decir, la Iglesia:

"“Unius uxoris virum". Si ad litteram respicias, bigamiam condemnat [...] Si vero allegoricis sentiatur sensibus, inhibet episcopo duas habere uxores, id est, ne post catholicum dogma, sensum haereticum sumat: sed Christianae tantum sinceritatis sibi associet fidem, ut unius uxoris tantum, id est, Ecclesiae, vir, episcopus appelleturs ${ }^{54}$.

${ }^{51}$ Cf. Albert Blaise, Dictionnaire latin-français des auteurs chrétiens (Turnhout: 1954-1967), 623, 861.

52 Cf. PL 22,658ss.

53 Cf. PG 125,41.

54 PL 139,172. 


\section{6. «UTILITATIS CAUSA»}

El arraigo y la difusión del coniugium spirituale entre obispo e Iglesia a partir del siglo IX se debe, sobre todo, a la Collectio Pseudo-Isidoro o Falsas Decretales. Su autor, el llamado Isidorus Mercator o Pseudoisidoro, compila lo mejor de las colecciones canónicas precedentes junto a cien decretales inventadas, elaborando una obra crucial, considerada auténtica hasta el siglo XVII.

Hoy es comúnmente aceptado su origen en la Galia carolingia $(847 / 852)^{55}$, donde en las diócesis predominan largas vacantes de sede o la presencia simultánea de más de un obispo. También algunos prelados, por su indignidad, son expulsados violentamente por su propio pueblo. En este contexto, se revela urgente una reforma disciplinar, en la cual juega un rol esencial la estabilidad y la autoridad efectiva del obispo en su diócesis ${ }^{56}$. Para ello resulta útil la invocación del argumento sobre la prohibición del traslado de los obispos basado en el vínculo conyugal que les une a su iglesia ${ }^{57}$.

Las decretales de la Collectio Pseudo-Isidoro que tratan explícitamente esta idea son las atribuidas a los papas Calixto $(\dagger 222)$ y Evaristo $(\dagger 105)$.

La primera, la "pseudo Calixto», trata sobre el principio de fijeza de las circunscripciones eclesiásticas y sobre la disciplina de las competencias. En ella se expone que, así como una esposa está vinculada a su marido mientras vive, y nadie puede juzgarla ni disponer de ella sin el consentimiento marital, la intromisión de un obispo en los asuntos de otra iglesia sin el consenso de su pastor — juzgando, o realizando ordenaciones $\mathrm{u}$ otras acciones de disposición- es un acto de adulterio:

«Sicut alterius uxor nec adulteraria ab aliquo, vel judicaria ut disponi, nisi a proprio viro, eo vivente, permittitur, sic nec uxor episcopi, quae eius ecclesia vel parochia indubitanter intelligitur, eo vivente,

${ }_{55}$ Cf. Paul Fournier y Gabriel Le Bras, Histoire des collections canoniques en Occident depuis les fausses décrétales jusqu'au decret de Gratien, I (Paris: Sirey, 1931-1932), 145-171; Clarence Gallagher, Church law and church order in Rome and Byzantium: a comparative study (Aldershot: Ashgate, 2002), 49-55.

56 Cf. Gallagher, 5-49; Agostino Marchetto, "Episcopato e primato pontificio nelle decretali pseudo isidoriane: ricerca storico-giuridica” (Tesis de doctorado, Pontificia Universidad Lateranense, 1971), 7-11.

57 Cf. Marchetto, 1-40; Fernando Yarza, El obispo en la organización eclesiástica de las decretales pseudoisidorianas (Pamplona: EUNSA, 1985), 181-193. 
absque eius judicio et voluntate alteri judicari vel disponi aut eius concubitu frui, id est ordinatione conceditur. Une ait Apostolus: Alligata est uxor legi, quamdiu vir eius vivit, eo vero defuncto, soluta est a lege viri. Similiter et sponsa episcopi (quia sponsa uxorque eius dicitur ecclesia) illo vivente ei est alligata: eo vero defuncto soluta est ${ }^{58}$.

El texto continúa: al igual que la mujer que toma otro esposo mientras vive su marido es separada de la comunidad como adúltera, así el obispo que acoge otra iglesia por su cuenta, tiene que ser expulsado como adúltero. No obstante, si el obispo es perseguido en su diócesis, entonces puede irse (cf. Mt 10,23), y también puede abandonarla si el paso a otra diócesis, utilitatis causa, aparece como necesario, y el obispo no lo hace de motu proprio sino fratribus invitantibus et auctoritate huius sanctae sedis ${ }^{59}$.

En la segunda decretal, la llamada "pseudo Evaristo», el título tradicional atribuido al obispo, "vicario de Cristo», sirve para reclamar la condición del sacerdote como representante de Cristo, poniendo de relieve que los obispos están unidos cada uno a su iglesia como Cristo está unido a la Iglesia, su Esposa. Asimismo, se afirma de nuevo que el obispo no debe ser adúltero abandonando a la iglesia para la cual ha sido nombrado sin que exista una urgente necesidad, absque inevitabili necessitate, o bien con el permiso de la Sede apostólica. Además, debe amarla y custodiarla castamente. Del mismo modo, la iglesia no puede abandonar o separarse de su obispo, sino que debe obedecerle y amarle, sin acoger a otro obispo cuando el suyo todavía está vivo, para no cometer delito de adulterio o fornicación:

«Sacerdotes vero vice Christi legatione funguntur in Ecclesia. Et sicut ei sua conjuncta est sponsa, id est Ecclesia, sic episcopis junguntur Ecclesiae unicuique pro portione sua. Et sicut vir non debet negligere uxorem suam, sed diligere et caste custodire, sic episcopus et multo magis custodire, et amare, atque prudenter regere debet Ecclesiam [...] ita Ecclesiae non licet dimittere aut ab ea segregare episcopum suum, ut alterum (vivente eo) accipiat, sed aut ipsum habeat, aut innupta maneat, id est, ne alterum episcopum, suo vivente, accipiat, ne fornicationis aut adulterii sui crimen incurrat ${ }^{60}$.

\footnotetext{
58 PL 130,133.

59 PL 130,134.

${ }_{60}$ PL 130,83-85.
} 
También en la Galia carolingia, el polémico arzobispo metropolitano Hincmarus de Reims ( $† 882$ ) se declara contrario a los cambios de sede de los obispos. En su carta De quibus apud se opone al traslado del obispo Actard de la diócesis de Nantes a la archidiócesis de Tours en el año $872^{61}$. El texto reclama ampliamente la estabilidad episcopal evocando la disciplina antigua: un solo obispo en una ciudad, que no debe buscar su traslado por avaricia o ambición de gloria, solo en caso de necessitate vel utilitate puede transferirse synodali disposizione, vel apostolicae sedis concesione ${ }^{62}$.

Para fundamentar tal disciplina, Hincmarus introduce la lógica nupcial: los mismos principios valen tanto para el matrimonio espiritual entre obispo e iglesia como para el matrimonio entre hombre y mujer. De este modo arremete contra el adulterio espiritual motivado por estar vinculado a dos sedes. Solo cuando el propio obispo muere, la iglesia vacante puede acoger un nuevo esposo que no tenga ninguna otra esposa de una unión precedente.

«Nos autem moderni et Gallicani episcopi, novos canones facere conamur, ut liceat nobis quod gravius est quam carnali commercio, spiritali adulterio, aut duas uxores, id est dues sedes simul habere, aut uxorem simul et concubinam tenere, vel vivente licet infirma uxore, id est Ecclesia nostra persecutione qualibet rebus ac possessionibus imminuta, ad alterius copulam trasmigrare. Cum sicut vir non habet potestatem corporis sui, sed mulier, quandiu uxor ejus licet infirma vivit, ita et episcopus non habet potestatem ecclesiam, videlicet plebem suam deserere, et alteram invadere vel usurpare ${ }^{63}$.

\section{ARMA REFORMISTA}

A través de la amplia difusión de las Falsas Decretales, de la mitad del siglo IX a la mitad del siglo XI, las colecciones canónicas aceptan, en general, el simbolismo del matrimonio espiritual entre el obispo y su iglesia $^{64}$. Por ejemplo, en la primera parte de la Collectio 44 capitulorum

${ }^{61}$ Cf. PL 126,210-230; Cf. Mary E. Sommar, "Hincmar of Reims and the Canon Law of Episcopal Translation", Catholic historical review 88 (2002): 429-445; Cf. Brown, 246.

62 PL 126,213.

63 PL 126,226.

${ }^{64}$ Cf. Gaudemet, "Le symbolisme du mariage", 114-115. 
De Episcoporum transmigratione (v. 872) se reproducen las tesis de las Falsas Decretales:

«Sicut vir non debet adulterare uxorem suam, ita nec episcopus ecclesiam suam ut illam dimittat ad quam sacratus est, absque inevitabili necessitate et absque apostolica vel regulari largitione et alteri se ambitus causa coniungat ${ }^{65}$.

También durante la Reforma gregoriana, las Falsas Decretales fueron usadas ampliamente y, aunque el matrimonio espiritual entre obispo e iglesia no parece ser considerado como visión oficial de la Iglesia ${ }^{66}$, su presencia en múltiples fuentes denota su popularidad. Desde el punto de vista del programa reformador deviene útil como «arma» para la cruzada contra los abusos doctrinales y disciplinares de la época.

En efecto, el modelo del matrimonio consensual, monógamo, enamorado y disoluble solo por la muerte se usa como inspiración para el establecimiento una disciplina universal: por una parte, a nivel intraeclesial, en el caso de las controversias sobre las elecciones pontificales ${ }^{67}$ y en la campaña a favor del celibato clerical, punto central de la Refor$\mathrm{ma}^{68}$; por otra parte, para hacer frente a la autoridad política secular, particularmente en el tema de las investiduras laicas, a menudo relacionadas con el delito de la simonía ${ }^{69}$.

65 Joannes P. Pozzi, De Episcoporum transmigratione et quod non temere judicentur regule quadraginta quattuor (Tesis de Doctorado, Pontificia Universitas Lateranensis, 1959), 14.

${ }^{66}$ Cf. Mary E. Sommar, "Innocent III's Doctrine of Spiritual Marriage”, en Sacri canones servandi sunt. Ius canonicum et status ecclesiae saeculis XIII-XV, ed. Pavel Kraft (Praga: Obra Instituto històrico de Praga, 2008), 485.

67 El polemista Auctor Gallicus, partidario de la Reforma, describe estas luchas por el poder primacial en el tratado De Ordinando Pontifice (v. 1048), y basándose en la ley canónica sobre el matrimonio y en los textos del Pseudo-Isidoro sobre la metáfora, el autor cuestiona la legitimidad de la elección de cinco papas entre 1045 y 1047. Cf. MGH Ldl. I,9-11.

68 Cf. Alfons M. Stickler, "El celibato en Occidente en la Edad Media", en Sacerdocio y celibato, Biblioteca de Autores Cristianos, ed. Joseph Coppens (Madrid: BAC editorial, 1972), 326; Cf. Christopher N. L. Brooke, Il matrimonio nel Medioevo (Bologna: Il Mulino, 1991), 69-111.

${ }^{69}$ Cf. Megan McLaughlin, "The Bishop as Bridegroom: Marital Imagery and Clerical Celibacy in the Eleventh and Early Twelfth Centuries", en Medieval Purity and Piety, Essays on Medieval Clerical Celibacy and Religious Reform, ed. Michael Frassetto (New York: Garland pub., 1998), 220. 


\section{IGLESIA VIOLADA}

Durante los convulsos años de la Reforma gregoriana las citadas prácticas de la investidura laica y de la simonía son consideradas por algunos autores como violencia carnal contra la Iglesia esposa ${ }^{70}$.

La simbología sacral, sobre todo el rol de las insignias pontificales es muy relevante en las fuentes, especialmente la imposición del anillo episcopal por parte de los reyes, descrito por los polemistas como la alianza nupcial del obispo esposo: "Anulus officium sponsi signare videtur. [...] Regia quae dantur nequaquam sanctificantur» ${ }^{71}$. Ejemplo elocuente es el escrito del alemán Theodoricus, en el cual se narra el asesinato del arzobispo Conrado en 1066 antes de tomar posesión de la iglesia de Treverica, para la cual había sido nombrado. Conrado deja viuda a su iglesia sin haber podido ser ordenado como su esposo con la recepción del báculo y el anillo esponsal de manos del rey:

«Itaque saepedicti praesulis sui instinctu e consilio, martyr Christi ante futurus quam episcopus, adductus in medio et dignus acclamatus, suscepit a manu regia pontificatus insignia, sicilicet pastoralem baculum et sponsalem ecclesiae anulum, interim dum sacri crismatis unctione ordinaretur sponsus ecclesiae» ${ }^{72}$.

Diversos autores se posicionan contra las investiduras laicas y contra la simonía con lenguaje esponsal. El teólogo Gerhoh de Reichersberg $(\dagger 1169)$, en su obra In De edificio Dei, afirma que un monarca no puede conferir el anillo episcopal por simonía: la iglesia viuda no puede tomar un nuevo cónyuge mediando dinero ${ }^{73}$.

Un especial interés despierta la obra del cardenal Umberto de Silva Candida († 1061), Adversus Simoniacos, en la cual denuncia un hecho gravísimo: el obispo que toma el control de la diócesis de una manera impropia, sobre todo simoníaca, la viola y la convierte en una prostituta o en una esclava, perjudicando directamente a la esposa de Cristo:

${ }^{70}$ Cf. Gerd Tellenbach, "Libertas, Kirche und Weltordnung im Zeitalter des Investiturstreites", en Forschungen zur Kirchen - und Geistesgeschichte 7 (Stuttgart: Kohlhammer, 1936), 155-157; Cf. Robert L. Benson, The Bishop-Elect: a study in the medieval ecclesiastical office (Princeton: Princenton University Press, 1968), 123-124.

${ }^{71}$ MGH Ldl. III,716-717. Otros ejemplos similares: MGH Ldl. III, 724; MGH Ldl. III, 726-727; MGH Ldl. III,721.

72 MGH SS. VIII, 215.

73 Cf. MGH Ldl. III,171. 
«Ex qua animadversione intellegitur, quam abiecta et ignobilis sponsa Christi reputetur, cuius inurias nemo qui doleat invenitur, cuius pudicitiam sacrilegis raptoribus prostitutam, venditam et addictam nemo qui defendat, nemo qui saltem illam ab eis eripiat et sponso vel constupratam restituat» ${ }^{74}$.

Además, el autor describe la administración de la iglesia a través de un laico como una violación de la esposa del sacerdote: «Incunctanter enim sacerdotis uxor ab aliis violatur, quandocumque ecclesia a laicis, quibus non pertinet, administratur vel ordinatur» ${ }^{75}$.

Finalmente, el obispo Anselmo de Lucca $(\dagger 1086)$, férreo reformador del clero en su diócesis, escribe una carta titulada Liber contra Wibertum, en la cual explica que cuando Clemente III († 1191) se plantea la posibilidad de llegar a Roma o simplemente de entrar de nuevo en su sede de Ravena utiliza en sus razonamientos el concepto de iglesia constuprata $^{76}$, es decir, violada.

\section{MINISTERIO E INCESTO}

A partir de la perspectiva de la totalidad del ministerio del orden, desde antiguo se conceptualiza la "paternidad sacerdotal» como consecuencia, al menos implícita, del vínculo nupcial que contrae el sacerdote con la comunidad eclesial. Una paternidad vinculada a la fecundidad espiritual de la Iglesia Madre, que engendra hijos de Dios con la «colaboración» de sus ministros.

Algunos autores, siguiendo las huellas del pensamiento patrístico ${ }^{77}$, definen la paternidad espiritual del ministro vinculada a la obligación del celibato. Como consecuencia de considerar a los propios fieles hijos espirituales, el acto de tener relaciones sexuales con alguno de ellos es considerado delito de incesto.

${ }^{74}$ MGH Ldl. I,203.

75 MGH Ldl. I,211-212.

${ }^{76}$ MGH Ldl. I,520.

77 Cf. Laurent Touze, "Paternidad divina y paternidad sacerdotal", en El Dios Padre de Nuestro Señor Jesucristo, XX Simposio Internacional de Teología de la Universidad de Navarra, 21-23 abril 1999, ed. José L. Illanes, Javier Sesé et al. (Pamplona: Servicio de publicaciones de la Universidad de Navarra, 2000), 655-664. 
Esta perspectiva del «incesto espiritual» aparece implícita en la legislación del Codex Justinianus (529/534) donde se decreta que los hijos de los presbíteros nacidos después de la ordenación deben ser tratados como incestuosos $^{78}$. De hecho, el Codex explicita la necesidad de que el obispo esté unido matrimonialmente solo a la Iglesia, decretando que no debe cohabitar con una esposa, ni ser padre de familia, y que debe vincularse fielmente a la Santa Iglesia. En lugar de engendrar niños nacidos de uniones carnales, el obispo tiene que engendrar el conjunto del pueblo cristiano ortodoxo ${ }^{79}$.

Siglos más tarde, en Oriente, donde el carácter paternal de la jerarquía toma desde su origen un gran protagonismo teológico ${ }^{80}$, Jean de Dara, teólogo Jacobita $(† 825)$, remarca la paternidad de los presbíteros ante sus fieles introduciendo el concepto del incesto:

«Le prêtre est le père de tous les fidèles, hommes et femmes. Quiconque occupe cette dignité parmi les fidèles, s'il vient à se marier avec une femme, apparaît comme quelqu'un qui se marie avec sa propre fille» ${ }^{81}$.

En Occidente, en el contexto de las controversias sobre el celibato, se retoman similares razonamientos. El célebre doctor de la Iglesia, Pedro Damiano († 1072), considera al obispo padre de los miembros de su comunidad eclesial. El autor se dirige a un obispo ficticio arguyendo que, si como padre tuviera relaciones sexuales con cualquiera de sus hijas espirituales, sería culpable de incesto:

«Omnes quippe Ecclesiae tuae filii, tui procul dubio filii sunt [...] Porro cum tu sis vir et sponsus Ecclesiae tuae, quod utique perhibent et annulus desponsationis, et virga commissionis; omnes qui in ea regenerati sunt per baptismatis sacramentum, tibi quoque nihilominus astringuntur necessitudine filiorum. Qui ergo cum spirituali filia tua commitis incestum, qua conscientia Dominici corporis audes tractare mysterium ${ }^{82}$.

\footnotetext{
${ }^{78}$ Cf. Corpus Iuris Civilis, II, ed. Paul Krüger (Berlin: 1959), 30.

${ }^{79}$ Cf. Ibid., 12. 34.

${ }^{80}$ Cf. Theodore Strotmann, "El obispo en la tradición oriental", en El Episcopado y la Iglesia Universal, ed. Yves Congar y Bernard Dupuy (Barcelona: Estela, 1966), 287-302.

81 "Codificazione canonica orientale", 230.

82 PL 145,385. La idea se repite en el Liber Gomorrhianus del mismo autor, aplicada a las relaciones contra natura. Cf. PL 145,166-169.
} 
A finales del siglo XII, Filippo di Harvengt ( $† 1182)$, en su obra De continentia clericorum, explica que el sacerdote solo tiene a la Iglesia como esposa $^{83}$, y obtiene, a través de la predicación, descendencia espiritual:

«Ecclesia quippe virgo est [...]. Hanc sacerdos noster sibi uxorem debet accipere, hanc semine verbi Dei spiritaliter fecondare, de hac in nomine fratris defunti id est Christi filios generare. Ad hoc idem Christus apostolos ordinavit. [...] Eos quod ad regendum et instruendum Ecclesiam vice sua voluit sublimari, et ad generandum spiritales filios ordinari, sibi quoque vivendo voluit conformare, ut ex quo ad tam sanctum officium aspirarent, carnales a se complexus omnino relegarent, et solius Ecclesiae fecundandis profectibus incubarent» ${ }^{84}$.

\section{UNA ESPOSA PARADISÍACA}

Bajo el influjo de la Reforma gregoriana proliferan tanto partidarios como adversarios de la causa del celibato clerical. Las dos facciones interpretan suo modo los argumentos de la Tradición, el ejemplo de Cristo y de los Doce Apóstoles, los Concilios y la Patrística. En este contexto, algunos autores introducen el argumento del matrimonio espiritual entre obispo e Iglesia en la retórica con la cual formulan sus ideales reformistas sobre el celibato.

El impulsor de la Reforma, Gregorio VII, que prohibe ejercer el ministerio a obispos y presbíteros no celibatarios, no se remite a la metáfora, a pesar de usar con frecuencia los textos de las Falsas Decretales ${ }^{85}$. En una carta al arzobispo de Colonia, con el objetivo de reforzar el celibato de los clérigos en su provincia, el pontífice incluye la alegoría del matrimonio entre Cristo y la Iglesia, afirmando que el ministro debe ser necesariamente continente al servicio de la pareja pura y virginal: Cristo-Iglesia ${ }^{86}$.

Algunos reformadores, de manera directa e ingeniosa, resaltan la excelencia del celibato clerical acentuando la diferencia entre unirse a una

83 Cf. PL 203,752.

84 PL 203,741-742.

85 En la colección Dictatus Papae (1075) recoge 27 proposiciones sobre la jurisdicción del Primado. Entre ellas la regla por la cual solo el papa puede deponer o restablecer a un obispo; o también, según las necesidades, transferirlo de una sede a otra (Cf. MGH Ep. IV, 201-208).

86 Cf. MGH Ep. II, 223-225. 
mujer carnal y unirse a una esposa paradisíaca. El celibato es interpretado como «otra y más alta» forma de matrimonio ${ }^{87}$.

En esta misma linea, Pedro Damiano escribe una carta al papa Nicolás II († 1061) en la cual considera inaceptable la posibilidad de que el obispo se una a mujer que no sea su iglesia. En efecto, ser esposo de una iglesia tiene consecuencias: tener relaciones sexuales con una mujer se considera adulterio, esté o no legalmente casado con ella ${ }^{88}$.

A principios del siglo XII Ivo de Chartres ( $† 1116)$, el influyente compilador legislativo, describe al obispo como paraninfo o custodio de la esposa de Cristo, con la misión de purificar a la Iglesia y presentarla al Esposo celestial, siempre luchando contra el abuso de la incontinencia clerical ${ }^{89}$.

También es conocida una Saga del santo islandés Thorlák († 1193), la cual narra una aparición divina que convence a un futuro obispo de no casarse, ya que él ya está prometido a una esposa más noble y más bella, es decir, a su iglesia ${ }^{90}$.

Cabe remarcar que a partir del siglo IX se empieza a generalizar la imagen del presbyter también como esposo espiritual de la Iglesia ${ }^{91}$. Umberto de Silva Candida acusa a los presbíteros casados de infidelidad a su esposa celestial, usando el término adulterio para definir los matrimonios clericales tolerados en la Iglesia occidental ${ }^{92}$. Con similares razonamientos el monje Manegoldi de Lautenbach $(\dagger 1103)$ considera a Gregorio VII demasiado indulgente con los ministros casados, escribiendo extensamente contra la incontinencia de los clérigos en su Liber ad Gebehardum ${ }^{93}$.

87 Cf. McLaughlin, 222.

88 Cf. PL 145,385.

89 Cf. PL 162,206.

90 Cf. Stephan Kuttner, "St. Jón of Hólar: Canon Law and Hagiography in medieval iceland", en The History of Ideas and Doctrines of Canon Law in the Middle Ages, VIII (London: Variorum, 1980), 374.

91 Cf. Fuchs, 85ss; Carl Gerold Fürst, Cardinalis. Prolegomeni zur einer Rechtsgeschichte des römischen Kardinalskollegimus (München: Wilheim Fink Verlag, 1967), 49; Wilheim Üholf, "Die Zuständigkeit zur Weishespendung mit besonderer Berücksichtigung des Zusammenhangs mit dem Weihetitel und der Inkardination", en Münchener Theologische Studien. III, Kanonistische Abteilung 15 (München: Max Hueber, 1962), 21-22.

92 Cf. PL 143,996.

93 Cf. MGH Ldl. I,350ss. 
Asimismo, el teólogo Honorius d'Autun ( $†$ 1151) en su obra Offendiculum, introduce la alegoría matrimonial en el discurso sobre el celibato: el matrimonio de los grandes sacerdotes de la época de Aaron (cf. Lv 21,13-14) se toma como modelo de la unión del clérigo con su iglesia. Solo el clérigo puede desposar a una virgen, es decir, a una iglesia consagrada por un obispo católico, para tomar canónicamente, no una viuda, ni una prostituta obtenida por simonía, ni una divorciada abandonada por su legítimo pastor ${ }^{94}$.

A pesar de que la metáfora es utilizada para exhortar al clero a asumir vínculos nupciales celestiales, algunos autores la rechazan para así arremeter contra la imposición de la disciplina del celibato ${ }^{95}$.

Como premisa, conviene aclarar que la oposición pública y directa al celibato no es extraña en la época ${ }^{96}$. A modo de ejemplo, un Sínodo de París en 1074 declara el celibato insoportable e irracional ${ }^{97}$.

Los adversarios del celibato invocan los textos del Antiguo Testamento para argumentar que el matrimonio carnal de los clérigos sería no solo lícito, sino necesario y apoyado en la Ley divina. Siendo el matrimonio un acto completamente puro, símbolo del amor entre Cristo y la Iglesia, no es incompatible con el sacerdocio. Algunos afirman también que en el Nuevo Testamento se supone el matrimonio como práctica clerical, sobre todo en la interpretación literal de la prescripción por la cual los obispos deben ser unius uxoris virum.

Partiendo de esta óptica, el obispo Ulrico de Imola, en su Epistola de continentia clericorum (v. 1060) considera que no existen fundamentos en la Sagrada Escritura para la promulgación de una ley que obligue al celibato, y que el único esposo de la Iglesia es $\mathrm{Cristo}^{98}$. Ulrico defiende la intepretación literal del texto paolino que define al obispo como hombre de una sola esposa. A su parecer, con el objetivo de que nadie pueda referir la frase solo a la unión con la Iglesia, Pablo añade que si alguien

${ }^{94}$ Cf. MGH Ldl. III,40-41.

${ }_{95}$ Cf. John W. Baldwin, "A campaign to reduce clerical celibacy at the turn of the twelfth an thirteenth centuries", en Études d'histoire du droit canonique, dédiées a Gabriel Le Bras, II (Paris: Sirey, 1965), 1041-1053.

96 Cf. Francesco Quaranta, Preti sposati nel Medioevo. Cinque apologie (Torino: Claudiana, 2000), 7-13.

97 Cf. MANSI 20,437.

98 Cf. MGH Ldl. I,260. 
no es capaz de gobernar su propia casa, no podrá cuidar de la Iglesia de Dios (cf. 1Tim 3,5)

Otro defensor de la interpretación literal de la cita paolina es el Anónimo de Rouen o de York (v. 1100). Partidario del clero casado, atribuye el derecho de esposar a la Iglesia solo a Cristo, rechazando el trasbase del unius uxoris virum del matrimonio carnal del obispo con una mujer a su matrimonio espiritual con la iglesia:

"Quoniam et apostolus instituit, ut oportet episcopum esse unius uxoris virum. Quod minime instituisset, si adulterium esset, quod episcopus haberet simul et uxorem et ecclesiam, quasi duas uxores, ut quidam asserunt. Quod quia de scripturis sanctis non habet auctoritatem, eadem facilitate contempnitur, qua dicitur. Sancta enim ecclesia non sacerdotis uxor, non sponsa, sed Christi est, sicut Johanes dixit: Qui habet sponsam, sponsus est» ${ }^{100}$.

\section{EL ACENTO PASTORAL}

En el siglo XII se inicia la elaboración del Derecho Canónico clásico (1150-1350), fruto de la colaboración entre la autoridad legislativa universal de la Iglesia - Concilos y Decretales papales- y las Escuelas de derecho de los siglos XII al XIV.

En la Concordia discordantium canonum de Graciano (v. 1140), de indiscutible importancia en el desarrollo del derecho canónico en la Iglesia latina ${ }^{101}$, los textos sobre el Episcopado son más abundantes que en colecciones normativas anteriores ${ }^{102}$.

El maestro boloñés recibe en su obra el ius antiquum, basado en la eclesiología del primer milenio, acogiendo de colecciones anteriores diversos tipos de fuentes: decretales, cánones conciliares y textos de la Patrística. Al mismo tiempo introduce el ius novum, produciéndose en el texto un estado de cierta tensión entre dos comprensiones del episcopado ${ }^{103}$.

\footnotetext{
${ }^{99}$ Cf. MGH Ldl. I,256.

100 MGH Ldl. III,646.

101 Cf. Gallagher, 14ss.

102 Cf. Jean Gaudemet, Le gouvernement de l'Église à l'époque classique. II partie: le gouvernement local (Paris: Cujas, 1979), 45.

${ }_{103}$ Cf. Thibault Joubert, La formation du lien entre l'évêque et son Église dans les versions successives du Décret de Gratien (Tesis de doctorado, Institut catholique de Paris, 2010), 26.
} 
El Decretum examina la figura del obispo sobre todo en la segunda división de la $I$ pars, en un largo tratado en el cual presenta los fundamentos del orden y de la jerarquía ${ }^{104}$. Este texto comprende una especie de «espejo» o retrato del obispo, seguido de un breve tratado sobre la Institución episcopal que comprende la elección y la consagración.

En esta I pars Graciano trata sobre la prohibición de ordenar a un bígamo evocando la obra De bono conjugali de Agustín de Hipona. Apoyándose en la exigencia paolina de que el obispo sea hombre de una sola esposa, argumenta que esto significa la unidad de todos los pueblos en Cristo $^{105}$. La referencia más directa a la metáfora se menciona en la reproducción del decreto del Nicolás II († 1061) sobre la elección del obispo de Roma, en el cual se afirma que quien deserta de su iglesia es comparable a un hombre que deja huérfanos a sus hijos y abandona a su esposa ${ }^{106}$.

En la II pars Graciano se adentra en cuestiones prácticas y polémicas: la posibilidad de nombrar a un obispo para una iglesia que tiene a su obispo precedente todavía vivo; las disciplina sobre traslados episcopales; la renuncia; el estatuto del obispo coadjutor, etc. ${ }^{107}$ En este contexto, Graciano evoca la citada carta de Cipriano de Cartago que considera adúltero a Novaciano por querer ocupar la sede romana de la cual Cornelio es el legítimo titular ${ }^{108}$.

En la citación de las Falsas Decretales se pone de manifiesto la tradición del matrimonio entre el obispo y su iglesia, pero sin ningún desarrollo notable por parte del Magister ${ }^{109}$. También en el dictum que sigue al c. 11 se comenta la unicidad del obispo en su iglesia, pero sin alusión alguna a nuestra metáfora ${ }^{110}$.

104 Cf. D. 21-101.

105 Cf. D. 26, c. 2. En el siglo V la práctica celibataria es poco habitual, y seguramente Agustín no interpreta el texto bíblico según la analogía esponsal entre obispo e iglesia, sino simplemente en el sentido estricto de la monogamia del matrimonio carnal del obispo. También en un dictum Graciano introduce la exigencia de la monogamia interpretada literalmente no solo del obispo, sino de todos los clérigos. Cf. D. 84, dac. 5.

106 Cf. D. 23 , c. 1.

107 Cf. C. 7.

108 Cf. C. 7 , q. 1 , c. 6.

109 C. 7, q. 1, c. 11. 39; Cf. Jakob Ibounig, Sponsus vice Christi, Der Bischof als Darsteller des Christus-Bräutigams und die Konsequenzen für seine Rechtsstellung von der apostolischen Zeit bis Gratian (Tesis de doctorado, Pontificia Università Gregoriana, 1994), 97-104; Cf. Gaudemet, Le gouvernement de l'Église, 105-107.

110 Cf. C. 7, q. 1, dpc. 11. 
En su descripción icónica del obispo, Graciano se centra en otra metáfora íntimamente vinculada a la nupcial a lo largo de la historia: el solícito pastor unido a su rebaño, y no solo como gobernante formalmente preteneciente a un grado de la jerarquía ${ }^{111}$.

\section{2. «MUTUUS CONSENSUS»}

Partiendo principalmente del dosier que recoge las Falsas Decretales en el Decretum, y de decisiones papales posteriores, los decretistas inician un innovador despliegue del matrimonio espiritual entre obispo e Iglesia, consistente en argumentar la metáfora en base al derecho consensual del matrimonio entre hombre y mujer.

A tal labor contribuyen los conceptos del derecho matrimonial que está naciendo como ciencia canónica. En efecto, la madurez de la legislación canónica sobre el matrimonio llega al punto de un acuerdo general durante y después del pontificado de Alejandro III $(† 1181)^{112}$. Los decretistas aplican las teorias de la decretal Veniens ad nos ${ }^{113}$ a la configuración de las nupcias del obispo con su iglesia.

Como preludio a esta proyección de los decretistas destacan dos obras. La primera, la Summa Decretorum (1157/1159) de Rufino de Asís, que diseña paralelos entre las diversas fases del sacramento del matrimonio contraído por la mujer y el varón, y el contraído por Cristo y la Iglesia ${ }^{114}$. La segunda, la colección anónima franco-renana Summa Elegantius in iure divino seu Coloniensis (v. 1169) que da un paso adelante afirmando que el matrimonio espiritual se inicia en la elección del obispo y se consuma en su consagración: «sed quia spirituale matrimonium quod est inter spiritualem sponsum et sponsam, pontificem videlicet et ecclesiam, electione initiatur, consecratione consummatur» ${ }^{115}$.

${ }^{111}$ Cf. Gaudemet, Le gouvernement de l'Église, 45; Sommar, "Innocent III's Doctrine", 485.

112 Cf. James A. Brundage, Law, Sex and Christian Society in Medieval Europe (Chicago: The University of Chicago Press, 1987), 257ss.

113 Cf. $X, 4,1.15$.

114 Cf. Rufino, Summa Decretorum, (Paderborn: H. Singer, 1902), 440-449.

115 "Summa elegantius in iure divino seu Coloniensis", en Monumenta Iuris Canonici. Series A: Corpus Glossatorum, I, ed. Gerard Fransen y Stephan Kuttner (New York: 1969), 138-139. 
El más importante decretista, Ugucio de Pisa († 1210), enseña en Boloña a finales del siglo XII. En su grandiosa Summa Decretorum diseña una mística de la elección epispopal en base a la teoría consensual del matrimonio carnal. Todo gira entorno al desarrollo del procedimiento electivo, que se da en dos momentos esenciales: la nominación activa, es decir, el simple acto de elección por parte de los electores; y la nominación pasiva, es decir, el consenso del elegido. El autor, familiarizado con el principio romano-canónico por el cual el matrimonio se realiza por el consenso y no por el intercambio sexual, subraya que en el mutuus consensus se contrata el vinculum spirituale:

«Item electio dicitur vinculum quod ex mutuo consensu, scilicet, eligentium et electi, contrahitur inter eos. Cum enim isti consentiunt in illum et ille versa vice in illos, contrahitur inter eos vinculum spirituale ut ille iam dicantur sponsus istius ecclesie vel istorum clericorum et hec ecclesia sponsa ipsius $[\ldots]{ }^{116}$.

Ugucio también afirma que, después de la ordenación episcopal, la actividad de gobierno del obispo en su iglesia es comparable al intercambio sexual entre marido y mujer, es decir, a la carnalis commixtio, estableciendo una ecuación entre la administración eclesiástica y el intercambio sexual:

«Sicut enim in matrimonio carnali precedit matrimonium in desponsatione per verba de presenti et postea sequitur carnalis commixtio, sic et hic in mutuo consensu precedit matrimonium spirituale et postea sequitur quasi carnalis commixtio, cum iam ecclesiam disponit et ordinat $»^{117}$.

En consecuencia, prosigue el autor, así como el acto de administrar es comparable a la consumación del matrimonio espiritual, la inhabilidad del electo para ejercer sus poderes antes de ser confirmado se parece a la abstinencia sexual de un marido por la duración de la menstruación de la mujer o por el parto ${ }^{118}$.

116 D. 63 c. 10. Emmanuel Ríos, "El primado del Romano Pontífice en el pensamiento de Hugucio de Pisa Decretista”, Compostellanum 8 (1963): 69.

117 D. 63 c. 10 ; Cf. Benson, 399.

118 Cf. D. 63 c. 10. Vease los comentarios de: Benson, 127-128; Condorelli, Principio elettivo, 37-41; Kenneth Pennington, Pope and Bishops: the Papal monarchy in the twelfth and thirteenth centuries (Philadelphia: University of Pennsiylvania Press, 1984), 81-90; Condorelli, Principio elettivo, 37-41. 
A partir del original e intimista estilo de Ugucio, la tradición canónica posterior asume el concepto jurídico del mutuus consensus como constitutivo del matrimonio espiritual en el procedimiento electivo del obispo.

\section{3. «PLENITUDO POSTESTATIS»}

Lotario de Segni († 1216), estudiante en Boloña con Ugucio, antes de ser elegido pontífice no parece estar interesado en el matrimonio espiritual entre obispo e Iglesia ${ }^{119}$. En sus textos no aparecen referencias explícitas a este, si bien en su obra De sacro altaris mysterio describe el anillo episcopal como signo de fidelidad del obispo a su deber de custos et pedagogus de la esposa de Cristo ${ }^{120}$.

En el tratado De quadripartita specie nuptiarum Lotario explica los cuatro tipos de matrimonio según una profunda teología nupcial: entre el hombre y la mujer; entre Cristo y la Iglesia; entre Dios y el alma justa; y, finalmente, entre el Verbo y la naturaleza humana ${ }^{121}$. También aparece un interesante fragmento sobre el Apostolicus ordo, el orden episcopal, el cual recibe a la esposa de Cristo para gobernarla no como sponsus, sino como amicus sponsi. Así, a través de la predicación, el orden episcopal genera descendencia en la Iglesia esposa:

«Id est Apostolicus ordo, qui sponsam Christi, scilicet sanctam Ecclesiam regendam suscepit; qui non sponsus sed amicus sponsi est. [...] Cujus praedicatione (Apostolicus ordo), multitudo gentium intravit ad fidem: et habet nomen defunti, quia conversus ad fidem nomen accipit crucifixi, ut a Christo cristiani dicantur» ${ }^{122}$.

119 Cf. Sommar, "Innocent III's Doctrine", 487.

120 Cf. PL 217,796.

121 Cf. PL 217,921-948. Cf. Wilhelm Imkamp, Das Kirchenbild Innocenz'III, 11981216 (Stuttgart: Hiersemann, 1983), 212-300; Cf. Isabelle Engammare, "Il trattato de quadripartita specie nuptiarum, e la parentela spirituale del Cristo con la Chiesa", en Innocenzo III, urbs et orbi. Atti del Congresso Internazionale, Istituto storico italiano per il medioevo, Roma, 9-15 settembre 1998, I, ed. Andrea Sommerlechner (Roma: Società romana di storia patria, 2003), 340-351; John C. Moore, Pope Innocent III (1160/61-1216): to root up and to plant (Notre Dame: University of Notre Dame Press, 2009), 16-19.

122 PL 217,961.

ESTUDIOS ECLESIÁSTICOS, vol. 94, núm. 371, diciembre 2019, 743-784, ISSN 0210-1610, ISSN-e 2605-5147 
No obstante, a partir de su consagración papal en 1198 Inocenció III convierte la metáfora en una aserción de la doctrina y en un principio inspirador de la ley canónica, sometido con presteza al servicio del poder primacial. Todo ello plasmado en algunas de sus principales decretales, cartas y sermones.

En la decretal Quanto personam (1198) ${ }^{123}$, Inocencio III mantiene la nulidad del traslado del obispo Conrad di Querfurt llevado a cabo sin la autorización de Roma. Con ello el pontífice manifiesta que tiene el derecho de reserva sobre los traslados episcopales, argumentando que el obispo está unido a su sede por un matrimonio espiritual que, como la unión de dos esposos, no puede romperse. Al igual que solo Dios puede disolver el matrimonio humano, solo el sucesor de Pedro, vicario de Cristo, tiene la prerrogativa de liberar al obispo del vínculo que le une a su iglesia y trasladarlo. Para justificar este derecho, Inocencio precisa que el pontífice actúa como representante de Dios en la tierra: «non puri hominis, sed veri Dei vicem gerit in terris ecclesiarum necessitate vel utilitate pensata non humana sed divina potius auctoritate dissolvit».

En la más influyente de sus decretales, Inter corporalia $(1199)^{124}$, con base en la comparación entre el carnale y el spirituale coniugium, Inocencio reafirma que el traslado, la dimisión y la aceptación de la renuncia de un obispo a su diócesis es, por derecho divino, reservada causa maior a los pontífices. La argumentación parte de la diferenciación entre las cosas corporales y las espirituales: las primeras son más fáciles de destruir que de crear, las segundas son más fáciles de crear que de destruir. El vínculo de unión espiritual es más fuerte que el vínculo carnal, por eso Dios se ha reservado la disolución del matrimonio espiritual que existe entre obispo e iglesia, así como se ha reservado la disolución de la unión entre hombre y mujer:

«Quum ero fortius sit spirituale vinculum quam carnale, dubitari non debet, quin omnipotens Deus spirituale coniugium, quod est inter episcopum et ecclesiam, suo tantum illicio reservaverit dissolvendum, qui dissolutionem etiam carnali coniugii, quod est inter virum et feminam suo tantum iudicio reservavit, praecipiens ut "quod Deus coniuxit homo non separet"».

\footnotetext{
123 Cf. $X, 1,7,3$.
}

124 Cf. $X, 1,7,2$. 
Siguiendo en parte el esquema de Ugucio ${ }^{125}$, Inocencio III afirma que el matrimonio espiritual entre obispo e iglesia se inicia con la elección, se ratifica con la confirmación y se consuma con la consagración del prelado. Por lo tanto, el obispo elegido y confirmado, aunque todavía no haya sido consagrado, no puede abandonar la iglesia sin permiso del papa, ya que entre los electores y el elegido se ha contraído el coniugium spirituale:

«Sicut autem episcopus consecratus sine licentia Romani pontificis suam non debet ecclesiam derelinquere, sic et electus confirmatus preter eius assensum suam deserere nequit ecclesiam, cui est matrimonialiter alligatus: cum non debeat in dubium revocari, quin post electionem et confirmationem canonicam inter personas eligentium et electi coniugium sit spirituale contractum».

En la decretal Licet in tantum (1200) ${ }^{126}$, el pontífice repite la doctrina del esquema tripartito, describiendo el procedimiento electivo del obispo por el cual se realiza el coniugium spirituale: por la elección es initiatum, por la confirmación es ratum y por la consagración es consummatum. En este punto el pontífice se desmarca de la doctrina de Ugucio, el cual sitúa la consumación en el momento de la administración de la iglesia por parte del prelado.

Siguiendo la misma línea de razonamiento, la decretal Cum inter $(1200)^{127}$ puntualiza que, por el mutuo consenso entre electores y elegido, se establece un quasi coniugale vinculum spiritaliter de modo que, antes de la confirmación, el elegido sí puede dimitir, pero no los electores.

Entre el amplísimo elenco de cartas que escribe Inocencio III destacan tres que pertenecen a su primer año de pontificado, y que versan sobre los traslados episcopales. En la carta al arzobispo Bituricensi el autor insiste sobre la indisolubilidad del matrimonio espiritual entre obispo e iglesia iure divino ${ }^{128}$.

Cuando el pontífice escribe al obispo Hildesemensis, que había abandonado la diócesis por iniciativa propia dirigiéndose a la diócesis de Würzburg, repite de nuevo su doctrina: la disolución del matrimonio

125 Cf. Benson, 149.

126 Cf. $X, 1,7,4$. La misma doctrina se reproduce en la carta dirigida al obispo de Bamberg (Cf. PL 214,845).

127 Cf. $X, 1,6,21$.

128 PL 214,106. 
espiritual solo se produce por poder divino a través del romano pontífice que representa a Dios en la tierra:

«Non attendens quod veritas in evangelio prostetatur: quos Deus coniuxit, homo non separet. Potestatem transferendi pontifices ita sibi retinuit dominus et magíster, quod soli beato Petro vicario suo et per ipsum successoribus suis, speciali privilegio tribuit et concessit [...] Non enim homo, sed Deus separat, quos Romanus Pontifex (qui non puri hominis, sed veri Dei vicem gerit in terris) ecclesiarum necessitate vel utilitate pensata, non humana, sed divina potius auctoritate dissolvit» ${ }^{129}$.

Por último, en la carta dedicada a Bernardo de Balbi el pontífice usa su plenitudinem potestatem para aprobar un traslado. En efecto, los arzobispos de Milán y Ravenna con sus sufragáneos habían informado a Inocencio de la elección de Bernardo, obispo de Faenza, para la diócesis de Pavía. El pontífice responde aprobando su traslado de Faenza a Pavía por motivo de necessitas y utilitas, y por su autoridad divina como vicario de Cristo. Así pues, con un lenguaje similar al utilizado en la decretal Quanto Personam, Inocencio establece de nuevo las bases teóricas de las prerrogativas papales:

«Quod Deus conjunxit, homo non separet (Math. XIX,6) [...] Licet autem videri posset ex his quod summus pontifex spirituale matrimonium, episcopi scilicet et Ecclesiae, separare non possit, cum tamen ex consuetudine, quae est optima legum interpres, et sacris canonibus habeatur quod per cessionem, depositionem et translationem, quae soli sunt sedi apostolica reservata, super hoc plenam habeat potestatem sane intelligentibus id nullum dubitationis scrupulum generabit» ${ }^{130}$.

\section{DOBLE VÍNCULO}

Bernardo de Pavia († 1213), discípulo de Ugucio, empieza su carrera en Boloña como decretista publicando el opúsculo Summa de electione (1177/1179), en el cual explora la analogía entre el consenso del procedimiento electoral del obispo y el consenso marital ${ }^{131}$.

129 PL 214,306.

130 PL 214,291-292.

131 Cf. Bernardo de Pavia, Summa de electione, ed. Theodor Laspeyres (Ratisbona: 1860), 307-323. 
Años más tarde el autor inaugura la edad de los decretalistas ${ }^{132}$ cuando concentra sus enseñanzas y sus escritos en las decretales de los papas escribiendo su Summa Decretalium (v. 1190) ${ }^{133}$. Bernardo afirma que un obispo se convierte en esposo de su iglesia por su mutuo consenso ${ }^{134}$ y distingue tres etapas en el procedimiento electivo: electio initiatur in deliberatione, perficitur in pronunciatione, consummatur in confirmatio$n e^{135}$. El autor prosigue deduciendo importantes consecuencias jurídicas derivadas de este esquema ${ }^{136}$. En definitiva, cuando se llega a la consumación por la confirmación, ya no puede disolverse el vínculo nupcial, excepto a través de un proceso según el derecho canónico.

Enrico de Susa, el cardenal Ostiense (†1271), continúa desplegando y ampliando las ideas de Inocencio III, ayudando con sus comentarios a comprender las bases teóricas de la eclesiología del pontífice ${ }^{137}$. Por ejemplo, en las decretales Quanto personam e Inter corporalia, citando a Mt 19,6: quos Deus coniunxit, homo non separet, Inocencio III justifica su derecho exclusivo a disolver el matrimonio entre el obispo y su iglesia. El Ostiense interpreta la cita en el contexto de los traslados episcopales: el vocablo homo se aplica a todos los hombres, excepto al pontifice, que es superior, y el único con la garantía de un privilegio especial para actuar como Dios en la tierra ${ }^{138}$.

En relación a Inter corporalia, el autor ofrece una interesante interpretación de su doctrina: el obispo está unido a un doble vínculo matrimonial, uno con la iglesia particular, cathedralis; y otro - al cual el obispo accede mediante el primero- con la Iglesia universal, unitas fidei catholicae christianorum et ominum ecclesiarum. Cualquier cambio concerniente al vínculo con la iglesia particular no comporta la disolución del vínculo indisoluble con la Iglesia universal:

132 Cf. Kenneth Pennington, "The Decretalists 1190-1210", en The History of Medieval Canon Law in the Classical Period, 1140-1234. From Gratian to the Decretals of Pope Gregory IX, ed. Wilfried Hartman y Kenneth Pennington (Washington: CUA Press, 2008), 211-245.

133 Cf. Bernardo de Pavia, Summa decretalium, ed. Theodor Laspeyres (Ratisbona: 1860$)$.

134 Cf. Bernardo de Pavia, $X, 1,11,7$.

135 Bernardo de Pavia, $X, 1,6,7$.

136 Bernardo de Pavia, Summa decretalium, 7-8.

137 Cf. Pennington, Pope and Bishops,110ss; Condorelli, Principio elettivo, 37-41.

138 Cf. Enrico de Susa, X, 1, 7, 2. 
«Multis modis dicitur ecclesia: uno modo, unitas fidei catholicae Christianorum et omnium Ecclesiarum, simul unita, qui invisibilis est [...] Est autem et Ecclesia, scilicet cathedralis, unica et visibilis, cui spiritualiter alligatur, et matrimonialiter coniungitur, ut per hoc possit pervenire ad matrimonium prime, sive ut nomine prime intelligatur contractum. Quantumcumque ergo mutetur, quantumcumque trasferatur, numquam dissolvitur matrimonium inter prelatum et primam ecclesiam contractum, sed sempre firmum primum remanet, quamvis administratio mutetur $[\ldots] »^{139}$.

Para el Ostiense, seguidor de la escuela canonística de París, el matrimonium spirituale se inicia con la elección por parte del capítulo catedralicio en nombre de la Iglesia universal — gerit typum Ecclesiae generalis -; se ratifica por la confirmación por parte del metropolitano, que representa a Cristo — gerit vice Christi-; y se consuma por la consagración espiscopal. Esta tiene la función de consumar el doble matrimonio, con la Iglesia universal y con la iglesia cathedralis, así como la praestatio corporis tiene la función de consumar el matrimonio carnal, esencialmente constituido y perfecto con el intercambio del consenso de los contrayentes ${ }^{140}$ : «matrimonium inter episcopum et ecclesiam in electione initiatur, in confirmatione ratificatur, in consecratione consummatur».

Por último, cabe referirnos a la doctrina de Nicolás de Tedeschi, el Panormitanus ( $†$ 1445), considerado el más influente jurista del siglo $\mathrm{XV}^{141}$. El decretalista también considera que la consagración episcopal en el matrimonio espiritual tiene el mismo significado que la cópula en el matrimonio carnal. Es decir, el rito de consagración se convierte en la precondición para generar descendencia ordenando a nuevos clérigos:

«Nam sicut demum post copulam carnalem potest sequi consecutio filiorum in matrimonio carnali, ita in matrimonio spirituali demum, post consecrationem potest episcopus clericos ordinare» ${ }^{142}$.

139 Enrico de Susa, $X, 1,6$.

140 Esta tesis sobre la consagración episcopal como consumación del matrimonio espiritual entre el obispo y la Iglesia se repite en la doctrina decretalística, desde Sinibaldo dei Fieschi a Giovanni d'Andrea, desde Nicolò de Tudeschi a Antonio da Budrio. Cf. P. Fedele, "Primato pontificio ed episcopato con particolare riferimento alla dottrina dell'Ostiense”, Studia Gratiana 14 (1967): 350-361.

141 Cf. Kenneth Pennington, "Nicolaus de Tudeschis (Panormitanus)", en Niccolò Tedeschi, Abbas Panormitanus, e i suoi Commentaria in Decretales, ed. Orazio Condorelli (Roma: Il Cigno, 2000), 9-15.

142 Nicolás de Tedeschi, $X, 1,7,11$. 
A pesar de ello, entre el matrimonio carnal y el espiritual existen diferencias: en el matrimonio carnal no es necesaria una aprobación externa, basta que la Iglesia no encuentre un motivo obstaculizador. En el matrimonio espiritual, en cambio, es necesaria la aprobación de la persona elegida, y de la misma elección, por medio de la confirmación.

Según el Panormitanus una iglesia puede convertirse en viuda por dos motivos: si no está unida a ningún prelado como esposo, es decir vacante; o quasi viduata quoad quid, es decir, por alguna circunstancia externa, como la inutilidad del esposo para el uso matrimonial. De este modo, se puede llamar viuda a una iglesia que tiene un prelado electo y confirmado, pero no consagrado aún por alguna incapacidad suya.

El Panormitanus, igual que Inocencio III, considera que el matrimonio espiritual es más fuerte que el carnal:

«Spirituale matrimonium est fortius quam carnale ex eo, quod spirituale matrimonium advocat et trahit ad se coniuge interveniente communi consensu, etiam post carnalem copulam» ${ }^{143}$.

La argumentación consiste en el hecho de que, después de contraer matrimonio carnal, los esposos pueden contraer un matrimonio espiritual por el hecho de entrar en un monasterio, pero no al revés. El matrimonio espiritual, pues, imprime un carácter que permanece tras la muerte.

En definitiva, los principales decretalistas que han escrito sobre nuestra metáfora a menudo se inspiran en la regla: Solus papa transfert episcopos, difundida a traves del título De translatione episcopi $i^{144}$, que plasma la doctrina de Inocencio III, y es recogido en las decretales de Gregorio IX $(† 1241)$, colección compilada por Ramon de Penyafort $(† 1275)$.

\section{TEOLOGÍA Y MÍSTICA}

El prolífico monje Bernardo de Claravall ( $†$ 1153) escribe el tratado De moribus et officio episcoporum, en el cual subraya la importancia del servicio de los obispos en la Iglesia como vicarios de Cristo ${ }^{145}$. Respecto al tema del traslado y deposición de los prelados, el autor presupone la

143 Nicolás de Tedeschi, $X, 1,7$.

144 Cf. X $1,7$.

145 Cf. PL 182,829. 
autoridad del sumo pontífice en su plena potestad, sin mencionar nuestra metáfora ${ }^{146}$. No obstante, Bernardo describe repetidamente a la Iglesia como esposa de Cristo ${ }^{147}$ y al obispo como amicus sponsi ${ }^{148}$. Pero no solo el obispo, también el papa, el presbítero y el abad monástico son esposos $^{149}$, y tienen el encargo de cuidar a la amante y devota Iglesia en ausencia de su único Esposo. Si bien Bernardo no afirma explícitamente que el obispo sea el esposo de la Iglesia, sino solo el amigo del Esposo, existe una excepción: en el relato de una consagración episcopal conferida por san Malaquías, el autor describe el anillo episcopal como el que hace del nuevo obispo el esposo de su iglesia ${ }^{150}$.

Más adelante, en la plenitud de la Escolástica, Tomás de Aquino $(†$ 1274) muestra una cierta prudencia en la atribución del título de esposo al obispo, situándolo siempre en el contexto de la nupcialidad del único Señor Jesucristo. En un discurso de exégesis bíblica el autor define a Juan el Bautista y al obispo como amigos del Esposo ${ }^{151}$.

$\mathrm{Su}$ pensamiento es especialmente rico en matices. En ocasiones el Aquinate propone la nupcialidad como un simple paralelismo: el prelado frente a la iglesia se puede comparar a un padre frente a la hija o al esposo frente a la esposa: "prelatus ad ecclesiam sibi subiectam comparatur vel sicut pater ad filiam vel sicut sponsus ad sponsam» ${ }^{152}$.

En la cuestión sobre la reserva episcopal para la concesión de las indulgencias, Tomás considera que la iglesia puede compararse a una comunidad política o a una familia en la cual el obispo asegura la unidad. Por eso, solo él recibe el anillo de la iglesia como esposo y posee la plena potestad en la distribución de los sacramentos y la jurisdicción para conocer las causas, es decir, para juzgar como una personalidad pública ${ }^{153}$.

Debido a que el obispo es el único que tiene, en el interior de su iglesia, la genuina y plena representación de Cristo, él puede ser llamado

\footnotetext{
146 Cf. PL 182,286-287.752.

147 Cf. Yves Congar, "L'ecclésiologie de saint Bernard", Analecta Sacri Ordinis Cisterciensis 9 (1953): 136-190.

148 PL 182,350. 358. 428.

149 Cf. Congar, 171-172.

150 Cf. Bernard de Clairvaux, Ouvres complètes, Sources Chrétiennes 367 (Paris: Cerf, 1990) 266-269.

151 Cf. San Tomás, Super Io., cap. III, lect. XI.

152 San Tomás, In Quodlibet IV, q. 8, a. 4.

153 Cf. San Tomás, In IV Sent., dist. 20, q. 1, a. 4.
} 
con un título especial, como Cristo, el esposo de la Iglesia ${ }^{154}$, y puede recibir el anillo nupcial «en el lugar» de Cristo, siendo su iglesia, no propiamente su esposa sino la sponsa Christi: «Per anulum sacramenta fidei qua ecclesia desponsatur Christo: ipsi enim sunt ecclesiae sponsi loco Christi» ${ }^{155}$.

El autor considera que todos los ministros, incluidos el papa y los presbíteros, pueden llamarse esposos, pero esto no significa que existan diversos esposos, sino que todos son nombrados como un solo esposo de la Iglesia ${ }^{156}$. No obstante, presupone el matrimonio espiritual entre el obispo y su iglesia en un contexto más disciplinar, cuando pone de relieve que el obispo puede ser obligado por el papa a aceptar su designación, es decir, a contraer matrimonio espiritual con una iglesia: «Praeterea, pater spiritualis, scilicet Papa, potest compellere praecepto ad matrimonium spirituale, scilicet ad episcopatum accipiendum. Ergo et pater carnalis ad carnale matrimonium ${ }^{157}$.

Sin esta obligación peritet ecclesiasticus ordo, puntualizando la diferencia entre el servicio corporal propio del matrimonio carnal, y el espiritual como oficio público:

«Nisi enim aliquis posset cogi ad suscipiendum regimen ecclesiae, ecclesia conservari non posset; cum quandoque illi qui sunt idonei, hoc nolint suscipere nisi coacti. Et ideo dicendum, quod non est simile hinc inde: quia non est aliqua corporalis servitus in matrimonio spirituali sicut in corporali: est enim spirituale matrimonium, sicut quoddam officium dispensandae reipublicae» ${ }^{158}$.

El franciscano Buenaventura ( $†$ 1274) usa - parece ser que por primera vez en la historia ${ }^{159}$ - el título de esposo de la Iglesia aplicado al obispo en el seno de la cuestión sobre la reserva de la ordenación ministerial a los hombres. El autor pretende demostrar que el obispo representa a Cristo como mediador y que, como tal, debe ser representado por un varón. La imposibilidad de la hembra de recibir el orden sagrado

${ }^{154}$ Cf. San Tomás, In IV Sent., dist. 24, q. 3, a. 2, ad 3.

155 San Tomás, In IV Sent., dist. 24, q. 3, a. 3.

156 Cf. San Tomás, Contra impugnantes, pars II, cap. III ad 22.

157 San Tomás, In IV Sent., dist. 29, q. 1, a. 4, ad. 4.

158 San Tomás, In IV Sent., dist. 29, q. 1, a. 4, ad. 4.

159 Cf. Alberto Piola, Donna e sacerdozio: indagine storico teologica degli aspetti antropologici dell'ordinazione delle donne (Catalupa: Effatà, 2006), 230-236. 
es sostenida por el argumento que se refiere al obispo como esposo de la Iglesia:

«Item, ordines ilii praeparant ad episcopatum, si quis bene in illis conversetur; sed episcopus sponsus est Ecclesiae: ergo cum mulier non possit ad episcopatum provehi, sed tantum vir, alioquin sponsus non esset Ecclesia; ergo ad ordines antecedentes promoveri est tantum virorum $»^{160}$.

Al ser el obispo esposo de la Iglesia, la mujer no puede ser admitida al episcopado, pues no podría cumplir la función masculina de esposo de la Iglesia. En consecuencia, solo pueden ser admitidos los varones a los precedentes grados de ordenación, ya que estos preparan para el episcopado.

Respecto a la potestad de dispensar indulgencias, el autor distingue entre los obispos esposos - que suceden a Cristo generando su proley el sumo pontífice como esposo de la Iglesia universal, padre de todos sus hijos:

«Tales autem sunt episcopi, qui sponsi sunt et habent vim generandi filios et filias, id est perfectos et imperfectos, et inter hos Summus Pontifex, qui est totius universalis Ecclesiae sponsus et rector. Ideo omnes episcopi, qui habent prolem, possunt facere indulgentias, et Summus Pontifex precipue inter omnes, quia ipsi competit totius spiritualis thesauri dispensatio, secundum quod curam habet de tota Ecclesia et omnibus eius filiis. Unde omnes sunt eius filii, et ipse est pater omnium ${ }^{161}$.

\section{CONCLUSIONES}

En la exhortación espiritual con la cual hemos iniciado este artículo, el papa Francisco invita a los obispos a vivir vinculados esponsalmente a sus diócesis, con la solicitud pastoral debida. Cabe recordar que el actual Caerimoniale Episcoporum precisa que el obispo debe llevar siempre su anillo como signo de su fe y de su unión nupcial con la Iglesia, su esposa $^{162}$.

\footnotetext{
${ }^{160}$ San Bonaventura, In IV Sent., dist. 25, q. 1. a. 2.

161 San Bonaventura, In IV Sent., dist. 20, q. 3. a. unicus.

162 Caerimoniale episcoporum, n. 58.
} 
La metáfora descriptiva de un matrimonio espiritual contraído entre el obispo y su iglesia ve la luz en un canon alejandrino del siglo IV, en el contexto de la fijación de circunscripciones eclesiásticas, de la regulación de la disciplina y del incipiente diseño del instituto del espiscopado.

En su origen, su presencia, si bien poco lineal, se manifiesta en las diversas e interdependientes disciplinas a través de tres ejes: la asimilación - a menudo matizada - de los traslados de sede al delito de «adulterio espiritual», evidenciando así la indisolubilidad de la unión entre el obispo y su diócesis; la presencia en el léxico eclesiástico de la expresión ecclesia viduata para describir a la iglesia vacante; y la polémica intepretación alegórica de la cita de san Pablo unius uxoris virum, como fundamento de la propiedad esencial de la unidad del matrimonio espiritual entre obispo e Iglesia.

A partir del siglo IX la metáfora toma impulso de la mano de la colección canónica de las Falsas Decretales, con un claro objetivo reformador de la jerarquía. También entorno a la época de la Reforma gregoriana se la utiliza muy versátilmente para luchar contra las investiduras laicas y la simonía, y para alimentar la apologética, ya sea en contra o a favor de la disciplina del celibato eclesiástico.

Llegados al siglo XII, el Decretum de Graciano recibe pacíficamente los textos clave tradicionales que definen al obispo como esposo de su iglesia, pero incidiendo prevalentemente en la imagen icónica del obispo como Buen Pastor de su rebaño. Asimismo, de la mano de los decretistas, y especialmente de Ugucio, el matrimonio espiritual entre el obispo y su iglesia empieza a afianzarse sobre el derecho consensual del matrimonio entre hombre y mujer, a través de peculiares y sutiles analogías jurídicas.

Figura clave será Inocencio III, que acoge con amplitud la metáfora en sus escritos, usándola sustancialmente para argumentar con ahinco las prerrogativas del sumo pontífice en los traslados, renuncias y deposiciones episcopales. Sus teorías son extensamente comentadas por los decretalistas, aunque no todos coinciden en las mismas formulaciones, influidos por las matizadas divergencias doctrinales entre la escuela de Boloña y la escuela de París sobre el derecho matrimonial canónico.

En este contexto, es imperativo subrayar la doctrina del Ostiense sobre el doble vínculo matrimonial que contrae el obispo en su consagración episcopal: con la iglesia cathedralis, y con la Iglesia universal. Mientras su matrimonio con la Iglesia universal —a semblanza de la 
relación esponsal que une a Cristo y a la Iglesia - es indisoluble, el vínculo con la iglesia particular puede ser disuelto sin más consecuencias ${ }^{163}$.

De los siglos XIII al XV, el vínculo que une el obispo a su iglesia se debilita, por un lado, a nivel práctico, debido a la alarmante crecida de los traslados de sede con base en el uso de las reservas papales; a la implantación de los nombramientos episcopales por parte de Roma; y también a la falta de residencia de los prelados en sus diócesis.

A nivel teórico la conceptualización sobre la unidad e indisolubilidad del vínculo nupcial tradicional entre el obispo y su iglesia se va transformando. En el íter seguido por la metáfora en la época estudiada, destaca su desplazamiento - a partir de la explicitación decretalística del doble vínculo nupcial contraído por el obispo y de la evolución de la eclesiología como disciplina propia- de la dimensión local a la dimensión prevalentemente universal de la única Iglesia de Cristo. Asimismo, el espectro icónico del obispo como esposo — complementado desde su origen por la representación del obispo como padre y pastor- se amplía progresivamente, sobre todo a partir del siglo IX, a los demás grados del sacramento del orden.

\section{REFERENCIAS}

FUENTES Y ABREVIATURAS

AAS Acta Apostolicae Sedis

MANSI Sacrorum conciliorum nova et amplissima collectio

MGH Aa. Monumenta Germaniae Historicae Auctores antiquissimi

MGH Cap. Monumenta Germaniae Historicae Capitularia regnum Francorum

MGH Conc. Monumenta Germaniae Historicae Concilia MGH Ep. Monumenta Germaniae Historicae Epistolae

MGH Ldl. Monumenta Germaniae Historicae Libelli de lite imperatorum et pontificum

MGH SS. Monumenta Germaniae Historicae Scriptores

$163 \mathrm{Su}$ doctrina ha provocado discusiones hasta la actualidad relacionadas con la vasta y polémica cuestión del origen de la potestad de jurisdicción episcopal. Cf. Fedele, 350-367. 


$\begin{array}{ll}\text { PG } & \text { MIGNE, Patrología, Series graeca } \\ \text { PL } & \text { MIGNE, Patrología, Series latina } \\ X & \text { Decretales Gregorii IX }\end{array}$

Autores

Aquino, Tomás. Secunda secundae Summae Theologiae: ad codices manuscriptos vaticanos exacta, cum comentariis Thomae de Vio Caietani, o.p. Romae: 1895-1899.

Baldwin, John W. "A campaign to reduce clerical celibacy at the turn of the twelfth an thirteenth centuries". En Études d'histoire du droit canonique, dédiées a Gabriel Le Bras, II, 1041-1053. Paris: Sirey, 1965.

Bar Berika, Ebediesus. "Ebediesu Sobae id est Nisibis metropolitae collection canonum synodicorum". En Scriptorum veterum nova collectio e vaticani codicibus, X, dirigido por Angelo Mai. Roma: Collegium Urbanum, 1838.

Benites, María M. La consagración en el ordo virginum. Buenos Aires: Cerf, 2005.

Benson, Robert L. The Bishop-Elect: a study in the medieval ecclesiastical office. Princeton: Princenton University Press, 1968.

Bergoglio, Jorge Mario. "Discurso del Santo Padre Francisco a los participantes en el Congreso para los obispos de nuevo nombramiento organizado por la congregación para las Iglesias orientales", Sala Clementina, 19 de septiembre de 2013, consultado el 3 de abril de 2018. http://www.vatican.va

Blaise, Albert. Dictionnaire latin-français des auteurs chrétiens. Turnhout: 1954-1967.

Blazquez, R., Josep M. Soler, y Olegario González de Cardedal. El obispo en la Iglesia: una meditación. Madrid: San Pablo, 2002.

Brooke, Christopher N. L. Il matrimonio nel Medioevo. Bologna: Il Mulino, 1991.

Brown, Charles J. "The development of the concept of the spousal relationship between bishop and local church in the west to the ninth century". Tesis de doctorado, Pontificio Ateneo Anselmiano, 2009.

Brundage, James A. Law, Sex and Christian Society in Medieval Europe. Chicago: University of Chicago Press, 1987.

Buenaventura. Opera Omnia. Florentiae: Ad claras aquas, 1882-1902.

Caerimoniale episcoporum. Città del Vaticano: 1985. 
Clairvaux, Bernard. Ouvres completes, Sources Chrétiennes 367. Paris: Cerf, 1990.

Cochini, Christian. Origines apostoliques du célibat sacerdotal. Paris: Lethielleux, 1981.

"Codificazione canonica orientale, Fonti". En Serie II, Fascicolo III, Patriarchatus Constantinopolitani Acta Selecta, I, dirigido por Jean Oudot. Città del Vaticano: Typis Polyglotis Vaticanis, 1941.

Concilio Vaticano II. "Decreto sobre la formación sacerdotal, Optatam totius n.16, 28 de octubre de 1965". AAS 58 (1966).

Condorelli, O. "Ejercicio del ministerio y vínculo jerárquico en la historia del derecho de la Iglesia". Ius Canonicum 45 (2005): 493-496.

-. Ordinare-Iudicare. Ricerca sulle potestà dei vescovi nella Chiesa antica e altomedievale, secoli II-IX. Roma: Il Cigno, 1997.

—. Principio elettivo, consenso, rappresentanza. Roma: Il Cigno, 2003.

Corpus Iuris Civilis, II, dirigido por Paul Krüger. Berlin: 1959.

Dix, Gregory. Le ministère dans l'Église ancienne, des années 90 à 410. Neuchâtel: Delachaux et Niestle, 1955.

Engammare, Isabelle. "Il trattato de quadripartita specie nuptiarum, e la parentela spirituale del Cristo con la Chiesa". En Innocenzo III, urbs et orbis, Atti del Congresso Internazionale, Istituto storico italiano per il medioevo, 9-15 settembre 1998, I, dirigido por Andrea Sommerlechner, 340-351. Roma: Società romana di storia patria, 2003.

Fedele, P. "Primato pontificio ed episcopato con particolare riferimento alla dottrina dell'Ostiense". Studia Gratiana 14 (1967): 350-361.

Fournier, Paul y Le Bras, Gabriel. Histoire des collections canoniques en Occident depuis les fausses décrétales jusqu'au decret de Gratien, I. Paris: Sirey, 1931-1932.

Fuchs, Vincent. Der Ordinationstitel von seiner Entstehung bis auf Innozenz III. Bonn: Schroeder, 1930.

Fürst, Carl Gerold. Cardinalis. Prolegomeni zur einer Rechtsgeschichte des römischen Kardinalskollegimus. München: Wilheim Fink Verlag, 1967.

Gallagher, Clarence. Church law and church order in Rome and Byzantium: a comparative study. Aldershot: Ashgate, 2002.

Gaudemet, Jean. Il matrimonio in Occidente. Torino: SEI, 1987.

—. L'Église dans l'empire romain, IV-V siècles. Paris: Sirey, 1958.

- . "Le symbolisme du mariage entre l'évêque et son Église et ses consequences juridiques". Kanon 7 (1985): 110-123. 
—. Le gouvernement de l'Église à l'époque classique. II partie: le gouvernement local. Paris: Cujas, 1979.

Ghirlanda, G. "El valor del derecho canónico para la misión de la Iglesia”. Ius Communionis 6 (2018): 69-103.

Grégoire, Reginald. "Il matrimonio mistico". En Il matrimonio nella società altomedievale, II, Settimane di studio del centro italiano di studi sull'alto Medioevo, 24. Spoleto: Presso la Sede del Centro, 1977.

Hefele, Karl J. y Henri Leclerq. Histoire des Conciles, I, 2 partie. Paris: Letouzey et Ané, 1907.

Ibounig, Jakob. "Sponsus vice Christi, Der Bischof als Darsteller des Christus-Bräutigams und die Konsequenzen für seine Rechtsstellung von der apostolischen Zeit bis Gratian". Tesis de doctorado, Pontificia Universidad Gregoriana, 1994.

Imkamp, Wilhelm. Das Kirchenbild Innocenz'III, 1198-1216. Stuttgart: Hiersemann, 1983.

Jargy, S. "Ibn Djarir 'at-Takriti”. En Dictionnaire du Droit Canonique, 5, 1244-1254. Paris: Letouzey, 1953.

Joubert, Thibault. "La formation du lien, entre l'évêque et son Église dans les versions successives du Décret de Gratien". Tesis de doctorado, Institut catholique de Paris, 2010.

Kuttner, Stephan. "St. Jón of Hólar: Canon Law and Hagiography in medieval iceland". En The History of Ideas and Doctrines of Canon Law in the Middle Ages, VIII, 367-375. London: Variorum, 1980.

Marchetto, Agostino. "Episcopato e primato pontificio nelle decretali pseudo isidoriane: ricerca storico-giuridica". Tesis de doctorado, Pontificia Universidad Lateranense, 1971.

McLaughlin, Megan. "The Bishop as Bridegroom: Marital Imagery and Clerical Celibacy in the Eleventh and Early Twelfth Centuries". En Medieval Purity and Piety, Essays on Medieval Clerical Celibacy and Religious Reform, dirigido por Michael Frassetto, 209-237. New York: Garland pub., 1998.

Metz, René. La consécration des vierges: hier, aujourd'hui, demain. Paris: Cerf, 2001.

Monumenta Iuris Canonici, Series A: Corpus Glossatorum, I, dirigido por Gerard Fransen y Stephan Kuttner. New York: Fordham University Press, 1969.

-. Summa elegantius in iure divino seu Coloniensis. 
Moore, John C. Pope Innocent III (1160/61-1216): to root up and to plant. Notre Dame: University of Notre Dame Press, 2009.

Munier, Charles. Les Statuta Ecclesiae Antiqua. Paris: Édition-Études, 1960.

Ober, L. "Die Translation der Bischöfe im Altertum". Archiv für katholisches Kirchenrecht 88 (1908): 209-229.

Pavia, Bernardo. Summa decretalium, dirigido por Theodor Laspeyres. Ratisbona: 1860.

-. Summa de electione.

Pennington, Kenneth. Pope and Bishops: The Papal monarchy in the twelfth and thirteenth centuries. Philadelphia: University of Pennsylvania Press, 1984.

-. "The Decretalists 1190-1210". En The History of Medieval Canon Law in the Classical Period, 1140-1234. From Gratian to the Decretals of Pope Gregory IX, dirigido por Wilfried Hartman y Kenneth Pennington, 211-245. Washington: CUA Press, 2008.

—. "Nicolaus de Tudeschis (Panormitanus)". En Niccolò Tedeschi, Abbas Panormitanus, e i suoi Commentaria in Decretales, dirigido por Orazio Condorelli, 9-36. Roma: Il Cigno, 2000.

Piola, Alberto. Donna e sacerdozio: indagine storico teologica degli aspetti antropologici dell'ordinazione delle donne. Catalupa: Effatà, 2006.

Pozzi, Joannes P. "De Episcoporum transmigratione et quod non temere judicentur regule quadraginta quattuor". Tesis de Doctorado, Pontificia Universidad Lateranense, 1959.

Quaranta, Francesco. Preti sposati nel Medioevo. Cinque apologie. Torino: Claudiana, 2000.

Ríos, Emmanuel. "El primado del Romano Pontífice en el pensamiento de Hugucio de Pisa Decretista". Compostellanum 8 (1963): 65-99.

Rufino de Asís. Summa Decretorum. Paderborn: H. Singer, 1902.

Sommar, Mary E. "Hincmar of Reims and the Canon Law of Episcopal Translation”. Catholic historical review 88 (2002): 429-445.

- . "Innocent III's Doctrine of Spiritual Marriage". En Sacri canones servandi sunt. Ius canonicum et status ecclesiae saeculis XIII-XV, dirigido por Pavel Kraft, 479-489. Praga: Obra Instituto histórico de Praga, 2008.

Stickler, Alfons M. "El celibato en Occidente en la Edad Media". En Sacerdocio y celibato, Biblioteca de Autores Cristianos 326, dirigido por Joseph Coppens, 301-358. Madrid: BAC editorial, 1972. 
Strotmann, Theodore. "El obispo en la tradición oriental". En El Episcopado y la Iglesia Universal, dirigido por Yves Congar y B. D. Dupuy, 287-302. Barcelona: Estela, 1966.

Tanner, Norman, y Giuseppe Alberigo. Decrees of the Ecumenical Councils, I. London: Sheed \& Ward, 1990.

Tellenbach, Gerd. "Libertas, Kirche und Weltordnung im Zeitalter des Investiturstreites". En Forschungen zur Kirchen - und Geistesgeschichte 7. Stuttgart: Kohlhammer, 1936.

Touze, Laurent. L'Avenir du celibat sacerdotal et sa logique sacramentelle. Paris: Parole et silenci, 2009.

-. "Paternidad divina y paternidad sacerdotal". En El Dios Padre de Nuestro Señor Jesucristo, XX Simposio Internacional de Teología de la Universidad de Navarra, 21-23 abril 1999, dirigido por José L. Illanes, Javier Sesé, Tomás Trigo, Juan Francisco Pozo, y José Enériz, 655-664. Pamplona: Servicio de publicaciones de la Universidad de Navarra, 2000.

Trummer, Josef. "Mystiches im alten Kirchenrecht. Die geistige Ehe zwischen Bischof und Diözese". Oestereichisches Archiv für Kinchenrecht 2 (1951): 62-75.

Üholf, Wilheim. "Die Zuständigkeit zur Weishespendung mit besonderer Berücksichtigung des Zusammenhangs mit dem Weihetitel und der Inkardination". En Münchener Theologische Studien. III, Kanonistische Abteilung 15. München: Max Hueber, 1962.

Vogel, Cornelia. "Unidad de la Iglesia y pluralidad de las formas históricas de organización eclesiástica desde el siglo III al V". En El Episcopado y la Iglesia Universal, dirigido por Yves Congar y Bernard Dupuy. Barcelona: Estela, 1966.

Yarza, Fernando. El obispo en la organización eclesiástica de las decretales pseudoisidorianas. Pamplona: EUNSA, 1985. 